\title{
CONQUESTA, REPARTIMENT I COLONITZACIÓ DE MALLORCA DURANT EL SEGLE XIII: \\ UN ESTAT DE LA QÜESTIÓ
}

\author{
RICARD SOTO I COMPANY \\ Universitat de Barcelona
}

\begin{abstract}
SUMARI
1. La interpretació històrica d'en Quadrado.- 2. La historiografia contemporània "tradicional" de la conquesta i repoblament de Mallorca.- 3. El "trencament" amb la interpretació d'en Quadrado: a) Noves interpretacions del "feudalisme mediterrani" i de la "reconquesta" ibèrica. b) La història de Mallorca subvertida: Mayûrqa com a punt de referència. c) Cap a una nova interpretació de la conquesta i colonització de Mallorca.- 4. Cloenda: de nou Quadrado.- 5. Referències bibliogràfiques.
\end{abstract}

Per a Mallorca i les altres illes de l'arxipèlag balear, el segle XIII va suposar un canvi radical, una solució de continuïtat, que va venir de la mà de la conquesta catalano feudal iniciada al $1229 \mathrm{i}$ acabada al 1285. De fet, àdhuc les tres primeres dècades, durant les quals encara pervivia la societat musulmana, ja van ser de canvis, atesa la conquesta almohade de 599/1203. La magnitud de les transformacions introduides pels almohades, tanmateix, les ignorem ${ }^{\prime}$. La conquesta catalano feudal, en canvi, va eliminar una societat i va crear una altra. No és exagerat dir que va constituir el fet

'Hom assenyala, tradicionalment, la fi de l'aillament al qual el regne de les Illes Orientals es veié sotmès durant la guerra entre els Banû Gânîyya i els almohads, però poca cosa més.

"Anuario de Estudios Medievales", 26 (1996) 
més rellevant de la història de l'arxipèlag. Pràcticament la totalitat dels historiadors han palesat l'impacte decisiu de la conquesta catalana de les Balears ${ }^{2}$.

Durant el segle XIII, doncs, a Mallorca es va constituir una societat nova, que va adquirir la forma de reialme independent de la Corona d'Aragó. L'interés que pot tenir l'estudi del cas mallorquí excedeix de molt el de la història local, ja que la conquesta i articulació del regne de Mallorca (o Mallorques, més exactament) se situa com el primer capítol de l'"expansió" catalana cap a al-Andalus i cap a la Mediterrània, després del pròleg que hauria estat la conquesta de Lleida i Tortosa , a mitjan segle XII, i abans de la conquesta de València. Tant la societat precedent invadida (andalusina) com la forma en que la societat invasora (catalano-aragonesa-provençal) procedeix a la conquesta i colonització o "repoblació" s'assemblen, en tots els casos, però el resultat final és molt diferent, el que planteja un bon grapat de problemes per a la història comparada. Naturalment, la història comparada no es pot centrar tan sols en les diferències inicials, ja que es tracta d'un procés temporalment molt llarg. De fet, el gran trencament entre Mallorca i Catalunya, per exemple, sembla cosa del XV més aviat, quan la situació del camperolat mallorquí i català (de la Catalunya vella, però) sembla divergir a causa de, respectivament, una desfeta (forans) i una discutible "victòria" (Guadalupe). En canvi, València, amb la importància de la seva població musulmana, es pot considerar un cas diferent des de bon començament.

Aquest no és sinó un conjunt de problemes que es poden derivar de l'estudi de la història de Mallorca al segle XIII, encara que hi hauria d'altres, depenent dels enfocaments que s'hi doni. Per exemple, un tema recorrent és el del regne de Mallorca en sí, com a entitat políticament viable o no, molt lligat aquest aspecte al del comerç i la manufactura. Concretament, aquest ha estat l'enfocament que recentment li ha donat al tema David Abulafia (1996) ${ }^{3}$, plantejant la viabilitat del regne de Mallorques, és a dir,

\footnotetext{
${ }^{2}$ Podriem dir que aquest és un dels pocs acords interpretatius que hom hi troba. Una de les poquissimes salvedats és la que fa referència a l'estructura de la propietat agrària $i$ el tipus de conreus, afectada del síndrome de la "immutabilitat illenca". Però inclús per a aquesta interpretació, la conquesta va ser el fet de més relleu, no ja del XIII, sinó de tota la història balear.

${ }^{3}$ Sense ésser gens original, però, ja que això havia estat plantejat de la mateixa forma i amb la mateixa documentació per Antoni RIERA (1980 i 1986).
} 
qüestionant la intel-ligibilitat dels diversos dominis del regne com a una unitat econòmica, més que política.

L'objectiu d'aquest treball no és el de fer una recol-lecció de cites bibliogràfiques més o menys recents ${ }^{4}$. Tanmateix, cal remarcar que la qualitat de la bilbliografia de caràcter local o sectorial, sovint amb gran aparell documental, compta a Mallorca amb una llarga tradició, i aquesta "erudició" d'aparença modesta resulta, de vegades mot superior a la de moltes obres de pretensions interpretatives ${ }^{5}$. Més aviat em proposo plantejar

\footnotetext{
${ }^{4}$ Veure per exemple l'estat de la qüestió bibliogràfic publicat per M. RIU al "XIII Congrés de Història de la Corona d'Aragó" (1990).

${ }^{5}$ El que podriem qualificar de monografies i històries locals posà en circulació coneixements sobretot de tipus documental molt importants a l'hora de corroborar o modificar les opinions vigents sobre el tema. De fet, Quadrado només va aportar directament les seves publicacions comentades del Llibre del Repartiment i de les Cròniques, amb un aparell de precisions erudites inestimable, peró de dificilíssima comprovació. En canvi, obres puntuals com la Numismàtica balear o el Cronicon Mayoricense de Campaner són, de vegades, molt més útils a l'historiador per les aportacions documentals inèdites sobre temes específics de gran importància que les grans interpretacions poc documentades.

Dins d'aquest sentit modest, però sens dubte eficacíssim per a l'historiador, s'hi han d'incloure algunes de les històries locals o les publicacions de simples col-leccions documentals.

El "Bulletí de la Societat Arqueològica Luliana" (BSAL) durant el segle passat i principis de l'actual hi va tenir un paper molt important publicant sèries documentals tan interessants (imprescindibles, més aviat) com el Capbreu de Nunó Sanç transcrit i treballat per E.K. Aguiló, o l'estudi documental sobre les cavalleries fet per J. de Oleza, per posar només dos exemples representatius.

Les històries locals ocupen un paper destacat, des de les més antigues, com les de Rotger (Pollença) i Ensenyat (Andraitx) a les més recents, entre les quals mereixen especial atenció les de R. Rosselló Vaquer i Ll. Lliteres.

L'obra de LLITERES (1967) sobre Artà, és el primer estudi que conec que utilitzava de forma sistemàtica i massiva la documentació més extensa i descriptiva de l'Arxiu del Regne de Mallorca, l'Escrivania de Cartes Reials (ECR) L'estructuració de l'obra es basava en la reproducció dels documents localitzats pacientment per l'autor a l'Arxiu del Regne de Mallorca (ARM al llarg d'anys, i d'aquests documents, junt amb fragments de cròniques, etc., s'intentava reconstruir la història de la vila i terme d'Artà. Alguns capítols de l'obra eren particularment interessants, com ara l'intent de reconstrucció de les alqueries de l'antic juz' de Jartân, o l'estudi sobre el repartiment del districte, el llistat dels primers pobladors inferit dels documents, o els capítols dedicats a "Procedimientos y costumbres" (amb informació sobre aspectes com les tutories, matrimonis, testaments...) "El cultivo y producción de los campos" (amb exposició de les classes de contractes, conreus i drets reials), "precios" i "redención de los cautivos", sobre els esclaus musulmans. Hom pot dir que aquest llibre revela tots els temes que hom pot tractar amb la documentació estudiada, $\mathrm{i}$ fins $\mathrm{i}$ tot dona unes pautes metodològiques per al seu ús.

Poc més recentement, les nombroses obres de R.Rosselló Vaquer han seguit un camí molt semblant. En aquest cas, es tracta de regestes catalanes dels documents de I'ECR sobretot, perfectament citats $\mathrm{i}$ tan ben datats com és possible, $\mathrm{i}$ agrupades cronològicament en forma d'històries locals. L'espai territorial assolit per aquest historiador és immens: Felanitx, Porreres, Santanyí, Manacor, Inca... Algunes de les seves obres, que mereixen del propi autor el modestíssim qualificatiu d' "opuscle" van precedides d'una explicació introductòria tan breu com útil, però d'altres particularment Manacor al segle XIII contenen introduccions molt més
} 
una sèrie de qüestions, algunes noves, però la major part d'elles obertes des de fa molt. Al meu parer, aquest tipus de problemes s'agrupen entorn a tres qüestions claus: a) les característiques de la societat precedent i la seva influència i perdurabilitat, b) les qüestions referents a la forma en que es va produir la colonització, amb dos aspectes tan importants com el la repoblació efectiva i la qüestió de l'existència de relacions feudals o no, i c) l'estructuració política del nou regne. Aquestes qüestions es poden tractar per separat, però de fet estan absolutament interconnectades. No sols perquè la intel-ligibilitat d'una societat procedeix de la comprensió de diferents factors, sinó perquè difícilment hom pot entendre la Història, que és un producte ideològicament articulat $^{6}$ sense tenir ben en compte les interpretacions precedents, particularment les que han tingut una rellevància real. En aquest sentit, i pel que fa a la història medieval de Mallorca, la major part dels historiadors que s'hi han ocupat són de l'opinió de que aquesta, en funció dels seus orígens, difícilment es pot dissociar de la figura de José María Quadrado (1819-1896). De fet, totes les interpretacions relatives a aquest tema parteixen incialment del que es podria qualificar d'una interpretació bàsicament "quadradiana" (en el sentit de que és la figura de l'historiador

ambicioses de del punt de vista històric.

També mereixen ser citades, per la seva utilitat, algunes obres més o menys recents que constitueixen importants aportacions documentals. El recull de J. VIC i J. MUNTANER (1945) és una col.leccció de 273 documents inèdits entre 1229 i 1349, tan interessants com arbitràriament escollits.

Un intent de sistematitzar la publicació de la documentació més antiga de Mallorca el va fer L. Pérez amb el seu Corpus documental balear, que pretenia reunir tota la documentació del regnat de Jaume I, a la revista "Fontes rerum Balearium" (FRB). Malgrat haver-se deixat de publicar molt aviat (només van apareixer tres volums, de 1977 a 1980), l'autor va poder publicar una relació de 541 documents entre $1228 \mathrm{i} 1234$, publicats o inèdits, d'una utilitat extrema, ja que cobreixen tot el període estudiat.

Particularment remarcable per la cura de les transcripcions documentals és el treball de $\mathbf{P}$ MORA i L. ANDRINAL (1982). A més d'una molt correcta transcripció de 295 documents acompanyats d'un bon aparat crític, el llibre és una reconstrucció històrica d'una institució tan important per a la història medieval mallorquina com el monestir de la Real

La darrera aportació documental de consideració és la Remembrança de Nuno Sanç publicada per A. MUT i G. ROSSELLó BORDOY el 1993. Es tracta d'una peça bàsica per tal de conèixer la porció del més important dels magnats, ja que conté l'inventari de totes les seves explotacions als districtes de Bunûla-Mûsû, Manaqûr i Ciutat. Malgrat la seva importància, el fet de no contenir els noms dels porcioners beneficiaris de les explotacions, així com la deficient classificació d'aquestes (sistemàticament qualificades com a "rahals", sense distingir entre aquests i alqueries) el converteix en una font de menys interès que el Repartiment o l'ECR, tot i ser absolutament imprescindible.

${ }^{6}$ Resulta obligatori referir-se als ja llunyans treballs de J. FONTANA (1982) en aquest sentit, remarcant precisament la influència de la ideologia en la gestació de les grans corrents historiogràfiques. 
menorquí qui realment ha "creat" la interpretació "oficial" i comunament acceptada d'aquesta) ${ }^{7}$.

\section{LA INTERPRETACIÓ HISTÒRICA D'EN QUADRADO}

Encara que abans de Quadrado no existeix una interpretació globalitzant i coherent de la història de la conquesta i colonització de Mallorca (les obres anteriors, per interessants que resultin, difícilment es podrien considerar amb criteris historiogràfics actuals), l'historiador menorquí no va sorgir del no res. És evident que ja abans de Quadrado s'havia generat una "interpetació", i que ell, en definitiva, no fa sinó recullir-la, cristal-litzar-la. En aquest sentit, crec que resulta convenient ferne una ràpida repassada als coneixements directes més antics, pràcticament contemporanis d'ells, que són les Cròniques, particularment la Crònica del Rei en Jaume i la Crònica de Marsili, sens dubte els que més han influït en la forma de considerar els esdeveniments. La redacció en primera persona, en un to èpic i gairebé ingenu de la crònica jaumina, la fa particularment atractiva. A més, la forta personalitat d'un rei català que va aportar a la Història de Catalunya i dels països de parla catalana pràcticament els fets d'armes més victoriosos que aquests conegueren, fa d'ell i dels seus actes quelcom així com a mites fundacionals. Les valoracions que es desprenen de la Crònica del rei en Jaume han influit fortament la historiografia, però de manera que o s'ha acceptat sense crítiques i matisacions o, al contrari, s'hi ha volgut anar massa lluny, buscant-li interpretacions que poc o res tenen a veure amb el descrit. En concret, aquesta crònica s'ha utilitzat per demostrar el paper predominant de la figura del rei en l'empresa i/o (perfectament compatible i àdhuc complementari) el dels mercaders, el que val a dir que és el primer argument respecte el caràcter no feudal de la operació. Però

${ }^{7}$ Els primers treballs assenyalant la important aportació de Quadrado a la interpretació de la història de Mallorca des d'un punt de vista crític procedeixen de Jaume Portella (PoRTELLA, 1982, 1983, 1985-86 i 1994), de qui aquestes pàgines són, en molt bona mesura, tributàries. Els més recent treball publicat sobre Quadrado és el de G. ENSENYAT (1996), sense dubte ponderat $\mathrm{i}$ ben informat. A. MAS (en premsa a) ha treballat sobre la influència de determinats escrits de caràcter jurídic sobre Quadrado. 
aquest us resulta abusiu. La Crònica ${ }^{8}$, pel que afecta a Mallorca, comença amb el relat del banquet amb el mercader Pere Martell (capítol 47), al qual s'hi demanà informació sobre les Illes Orientals. Els que acompanyaven al rei eren

... la major partida dels nobles de Catalunya... don Nunyo Sanxes... e En Guillem de Montcada, e En Guerau de Cervelló, e En Ramon Alamany, e En Guillem de Clarmunt e En Bernat de Sancta Eugènia, senyor de Torroella. •

Aquests serien bàsicament els grans magnats que posteriorment participarien a la conquesta. La conclusió que els nobles van treure de la didàctica exposició del ciutadà Martell va ser que

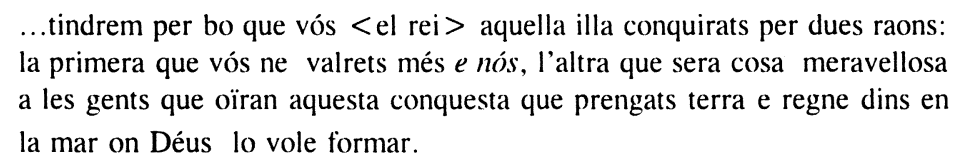

De tot l' espai dedicat per la crònica (caps. 43-48) a la preparació de l'expedició mallorquina, només la intervenció de Pere Martell pot donar peu a pensar en el predomini dels mercaders a l'hora de determinar-la, mentre que les intervencions dels nobles són constants. I d'aquestes no crec que es pugui desprendre una altra cosa que l'acord entre rei i magnats per obrir un front que els beneficiès a tots, després d'un complexe seguit de guerres feudals i del temporal fracàs de l'expansió cap a València.

Quadrado, historiador de principis/mitjans del segle XIX, insereix aquest relat històric dintre d'una especial forma d'entendre la Història (d'Espanya en aquest cas), que hom podria qualificar de "tradicional", remarcant particularment el pes del poder reial amb una clara funcionalitat política. La figura del rei, des de l'època dels Reis Catòlics, és glossada pels exègetes espanyols com a àrbitre de les lluites entre noblesa i burgesia, per una banda, i rics i pobres per l'altra. Aquesta idílica formulació del paper de la Corona forma part de la propaganda oficial ja des de l'"Estat" dels

\footnotetext{
${ }^{8} \mathrm{La}$ Crònica és la forma en que a partir d'ara citaré la Crònica del rei en Jaume o Llibre dels Feyts. De les edicions existents, he fet servir la que es titula Les quatre grans cròniques:Jaume I, Bernat Desclot, Ramon Muntaner, Pere III, de 1971, editada a Barcelona amb pròlegs i notes d'en Ferran Soldevila. Entre parèntesi es citen els capítols. Atès que la Crònica de Marsili, és molt menys citada, apareix sempre amb el seu títol sencer.
} 
Habsburg, però és recullida amb entusiasme pels historiadors conservadors espanyols, a la segona meitat del segle XIX, quan la polèmica amb els "progressistes" impeleix a la mitificació de l'estat absolutista tradicional, encarnació de totes les harmonies. Com fa palès J. Portella (Portella, 1985$87)^{9}$, les diferents actituts polítiques de l'època condicionen la forma de veure un problema que llavors era extraordinàriament vigent, com ara l'existència o no de feudalisme a Espanya. Els raonaments són en el fons molt senzills: si a Espanya no hi havia hagut feudalisme, la "revolució" propugnada per la burgesia liberal i el camperolat era pura subversió ideològica totalment ilegítima i innecessària. A Mallorca (o millor, al "Regne de Mallorques") la postura referida comptava amb un element que reforçava aquest paper d'àrbitre de la Corona, dins d'una societat no feudal, i era l'existència de la Carta de Franquesa atorgada pel mateix Jaume I poc després de la conquesta ${ }^{10}$. La Carta semblava abolir expressament les institucions feudals, ja que aquestes s'assimilaven exclussivament a la servitud, i la Carta mana expressament que els pobladors de Mallorca

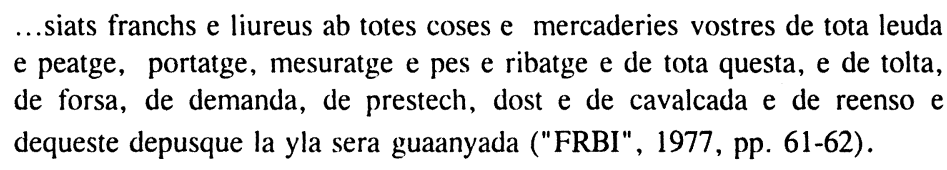

Tot i que la figura de Quadrado no està estudiada tan satisfactòriament com deuria, hom sap el suficient sobre aquest historiador ${ }^{11}$, arxiver del regne de Mallorca, que unia al seu pregon coneixement de les fonts documentals un autèntic projecte ideològic conservador, molt lligat als interessos dels grans terratinents de l'illa ${ }^{12}$. Inserit dins la gran polèmica que va generar la dissolució de l'Antic Règim, Quadrado va formar part del grup d'ideòlegs que, amb una finalitat eminentment pràctica (la conservació de determinats drets dels propietaris "feudals"), va negar l'existència de

\footnotetext{
${ }^{9}$ Portella segueix bàsicament l'argumentació de J. FonTANA (1982).

${ }^{10} \mathrm{~L}$ 'edició consultada ha estat la del FRB I (1977), pp. 59-66. El text, segurament el més conegut del segle XIII mallorquí, ha estat glossat i comentat per nombrosos historiadors.

"Particularment a G. ENSENYAT (1996).

${ }^{12}$ Quadrado és un home d'inteligència brillant, i aconsegueix que la seva argumentació pugui passar per lliberal-conservadora. De fet, és tan sols conservador, profundament conservadora, $\mathrm{i}$ el seu pretès lliberalisme és tan sols una qüestió formal. Per a aquests aspectes, vegeu PORTELLA (1985-86) i MAS (en premsa a).
} 
feudalisme a Mallorca. La inexistència d'aquest feudalisme, aleshores, no és una qüestió teòrica, sinó la part central d'un discurs polític conservador. Però Quadrado no és solament un ideòleg conservador ${ }^{13}$, sinó un historiador rigoròs ${ }^{14}$, i això li permet donar a les seves raons la solidesa d'un discurs històric molt ben documentat i perspicaçment argumentat.

Així, és Quadrado el primer historiador que teoritza sobre una societat no feudal a Mallorca. La seva Historia de la conquista de Mallorca, publicada el 1850, és l'obra de més volada dedicada al tema que ens ocupa, on són recollides les principals fonts documentals conegudes a la seva època (les Cròniques i el Llibre del Repartiment). Però és a les primeres pàgines de la seva obra "cabdal", Forenses y ciudadanos, publicada el 1847, on en dona les claus del seu pensament. Per començar, justifica l'expedició de forma més noble que no pas el rei i magnats, posant la motivació en les agressions dels pirates sarraïns. A la Crònica esmentada el rei, amb la seva ferotge ingenuitat, no necessita justificar res: l'hi sobra amb "meravellar" la gent adquirint un regne sobre la mar i incrementar el seu poder, encara que la Crònica també esmenta un afer piràtic.

Però Quadrado, que s'està interpelant sobre les causes de les revoltes pageses a Mallorca durant el segle XV (la revolta dels Forans) en una època en que bona part dels pagesos espanyols, malgrat la seva ideologia reaccionària, plantegen reivindicacions amenaçants per als propietaris (és l'època de la dicotomia camp carlí/ciutat lliberal), troba la resposta en l'oposició entre ciutadans $\mathrm{i}$ forans, sense feudals $\mathrm{i}$ "sin un rico-hombre apenas", oposició que serà creixent a partir de la "ruina del comercio de Levante" (p. 20). Aleshores els ciutadans adquiriren terres i contribuiren a l'empobriment dels colons, els "hidalgos de las villas y los más pudientes labradores" esdevingueren ciutadans, mentre que

\footnotetext{
${ }^{13}$ PORTELLA (1985-86, nota 4) explicava les relacions de Quadrado amb el carlisme i amb aristòcrates $\mathrm{i}$ intel.lectuals mallorquins contemporanis. Més recentment A. MAS (en premsa a) ha estudiat la influència, no solament ideològica, sinó també formal, que els polemistes més conservadors van tenir sobre Quadrado a l'hora de conformar la seva postura respecte la polèmica sobre l'abolició del règim senyorial.

${ }^{14}$ PORTELLA (1985-86) assenyala tant l'amistat que unia a Quadrado amb MenéndePelayo com la influència directa de Bossuet sobre aquest, el que conferiria a la seva obra un tó altamanet providencialista. Tanmateix, l'escrupolositat formal de Quadrado era molt considerable, a diferència dels historiadors mallorquins d'èpoques precedents. De fet, tal com explica FonTANA (1982) és entre finals del segle XVIII i principis del XIX quan apareix la "ciència" històrica, sobretot pel que suposa de crítica de fonts. A Espanya el retard és considerable, $\mathrm{i}$ els autoris citats són dels primers "historiadors" en el sentit modern de la paraula.
} 
...esclavos importados de Levante cultivaban las adquiridas propiedades, ahorrando al ciudadano y quitando al payés un miserable estipendio" (QUADRADO, 1847 , p. 21).

De fet, s'està descrivint la ruïna d'una societat mercantil que, amb el seu comerç interromput, ha de cercar ingressos substitutoris. Efectivament, Quadrado postula que Mallorca és, des de la conquesta "mercantil más bien que patricia", i la compara amb les ciutats italianes més que amb la resta de la Corona d'Aragó, tot i incloent-hi Barcelona (p. 20).

En definitiva, aquesta situació es basa en dos elements. El primer és l'absència de feudalisme a Mallorca. Quadrado identifica feudalisme amb grans magnats, i en aquest sentit assenyala l'absentisme d'aquests i els repartiments de terres que feren entre els seus. Però també afegeix que pocs dels "mesnaderos" s'hi establiren, de forma que van ésser els habitants de ciutats i viles els que realment van iniciar el repoblament de Mallorca, donant lloc a un model de societat força diferent al dels altres regnes de la Corona d'Aragó:

Ciudadanos y caballeros, sin un ricohombre apenas, fueron los pobladores de Mallorca; y sabido es que este brazo constituía en el reino de Aragón una especie de clase media" (Ibídem, p. 19).

Aquesta societat de "classe mitjana" es troba fermament assentada gràcies a un segon element, que són els "privilegios y fueros", generosament atorgats. Això generà un fluxe de població de les regions veïnes que provocà, al camp, una parcel·lació constant alhora que un gran creixement:

Semejante afluencia precipitó de tal suerte el fraccionamiento de la propiedad, que en 1300 con los establecimientos y ventas se habían trocado en populosas villas las que sesenta y ocho años antes figuraban todavía como simples predios" (Ibídem, p. 19).

Realment, el que fa Quadrado és exposar en molt breus paraules (de forma idealitzada, però), el desenvolupament d'un model de colonització el suficientment sòlid com per que encara tingui vigència en molts aspectes, puix que l'aportació de dades documentals corrobora moltes de les seves afirmacions. No de bades en Quadrado, arxiver de l'Arxiu del Regne de Mallorca (ARM), coneixia força bé la documentació continguda en aquest. Ademés, Quadrado percep clarament el problema de l'empobriment dels 
colons "abrumados así por las cargas enfitéuticas como por el peso de los impuestos" (p. 20).

La interpretació quadradiana de la història del període subsisteix gairebé sense variacions fins a l'actualitat, ja que l'obra recent més ambiciosa a aquest respecte, la Historia de Mallorca, coordinada i dirigida per J. Mascaró Pasarius ${ }^{15}$ ofereix, de fet, el mateix esquema interpretatiu dissenyat per Quadrado. És clar que el tema de la conquesta i colonització de Mallorca va ser tractat per nombrosos autors, però de fet cap d'ells no va fer una aportació global tan important com la de Quadrado.

\section{LA HISTORIOGRAFIA CONTEMPORÀNIA "TRADICIONAL" DE LA CONQUESTA I REPOBLAMENT DE MALLORCA}

L'any 1970 es començà la publicació de la ja citada Història de Mallorca, projecte ambiciòs i amb una gran quantitat de mitjans materials. Encara que aquesta obra intentava assolir tots els aspectes cronològics (i molts simplement temàtics, el que fa d'ella més una miscel·lània que allò que pretén el títol) de la història mallorquina, era la història medieval i moderna la que comptava amb més aportacions, i més ambicioses.

L'esquema seguit en les diverses col-laboracions al respecte és fonamentalment quadradià, en el millor dels casos. J. Company (1975), per exemple, després de fer una llarga repassada a l'estat de la Corona d'Aragó abans de la conquesta de Mallorca en que segueix fonamentalment les cròniques i l'obra de F. Soldevila (1971, pp. 1-48), explica els fets bèl-lics tot seguint les esmentades cròniques i l'estudi militar de Ribas de Pina (1934). De fet, el títol de la seva col-laboració s'ajusta bé al seu contingut.

J. Salvà (1975) fa un estudi molt més ambiciòs, des d'un punt de vista jurídic. De fet, analitza la Carta de franquesa, la qual considera com a factor garant de llibertats al regne de Mallorques, per oposició a un codi eminentment feudal com ara els Usatges, vigent a Catalunya però no a Mallorca en la seva opinió. Més encara, el context a Catalunya era ja de superació del feudalisme, que l'autor assimila amb el règim vassallàtic, dins de la més pura ortodoxia juridicista ganshofiana (pp. 376 i ss.), i amb la

\footnotetext{
${ }^{15}$ Editada el 1970, aquesta obra encara esta en vigència dins de Mallorca, ja que si no no s'entendrien les successives reedicions, la més recent en forma de fascicles $\mathrm{i}$ amb una posta al dia mínima i circumstancial.
} 
servitud remença, tot seguint Hinojosa (Ibidem). L'expansió de la reconques$\mathrm{ta}$, amb el règim de municipalitats, i la concesió de cartes pobles $\mathrm{i}$ de franquesa, seria l'element primordial en aquest retrocès del feudalisme (p. 382), juntament amb l'increment polític del poder reial, ja no necessitat dels pactes vassallàtics. Això quedaria definitivament definit a les Corts de Barcelona, en que s'acordà la conquesta de Mallorca:

De todo lo expuesto puede sacarse la conclusión de que las Cortes de Barcelona de 1228 fueron privativas del principado de Cataluña y que en ellas se acordó la conquista de Mallorca como empresa exclusiva de los catalanes en virtud de unos ofrecimientos espontáneos de los señores, prelados y ciudades; no por virtud de los deberes feudales, sino por vía de acuerdo paccionado que se redujo a escitura, en cuyas cláusulas hubo convenio recíproco entre el rey y los magnates (SALVȦ, 1975, p. 368).

Salvà, emperò, encerta al meu parer en una qüestió fonamental respecte la forma de l'establiment "emfitèutic" i la seva relació amb el dret feudal, i no amb el romano-bizantí:

\begin{abstract}
...debemos considerar, en nuestra modesta opinión, que, con el renacimiento y difusión del derecho romano en el siglo XII, las instituticones medievales fueron revestidas por los juristas de nuevas formas jurídicas, tratando de hallar su figura más apropiada en el vasto campo de la jurisprudencia clásica. Así por ejemplo, el vasallaje feudal tuvo su equivalencia en la clientela, la redención de la servidumbre adoptó las fórmulas de la manumisión de la esclavitud y el contrato de establecimiento de tierras en arredamiento perpetuo se configuró en la enfiteusis (Ibidem, p. 377).
\end{abstract}

Dins de l'esmentada Història de Mallorca apareixen alguns treballs de l'historiador A. Santamaría, treballs que han tingut una continuitat en altres publicacions (Víd. Bibliografia). Santamaria interpreta la història de la conquesta, repoblació i estructuració del regne de Mallorques d'una forma que podria dir-se "neo-quadradiana". La conquesta de Mallorca no és una conquesta feudal, sinó

...una empresa asociada colectiva, con claras connotaciones de naturaleza jurídica comanditaria desde mentalidades que, aunque dentro de un mundo feudalizado, ofrecen exterioridades que pueden valorarse como precapitalistas" (SANTAMARía, 1981, p. 17). 
Les característiques d'aquesta societat són bàsicament les mateixes que per a Quadrado, ja que es tracta d'un a societat no feudal, encara que admeti que posseeix trets feudals, atès que existeix "un régimen señorial muy condicionado", ja que predomina totalment el reialenc:

Tras la conquista se implanta en Mallorca una estructura de la propiedad agraria basada en el realengo y también en las repoblaciones promovidas por comunidades colectivas urbanas, basada en la mediana y pequeña propiedad alodial, es decir, libre de cualquier servidumbre de cualquier género al amparo de la Carta de Franqueza. ¿Y en los dominios señoriales? Obran datos escasos, pero los que constan sugieren que también los barones al repartir sus dominios asentaron mayoritariamente pequeños y medianos propietarios alodiales o pequeños tenedores enfiteutas (SANTAMARÍA, 1981, p. 25).

Aquesta societat és definida per Santamaría com a "lliure":

...la institucionalización del reino de Mallorca no se produce prioritariamente bajo el signo retrógrado de servidumbres feudalizantes, vigentes pero ya en crisis a la sazón en Occidente,, socavadas por la dinámica del cambio histórico, aunque permanecieron operantes en ciertos lugares del campo catalán, sino prioritariamente bajo el signo progresivo de la libertad; (Ibídem, pp. 17-18)

En definitiva, la causa de tot això seria el fet d'ésser Mallorca un àrea de frontera, ja que

...la repoblación de un área tan estratégica com la balear, marcada por las circunstancias propias, siempre arriesgadas, de las tierras fronterizas (en su caso peculiarizadas por los condicionamientos de la insularidad, que comportaba resgos adicionales, no podía planificarse...sino desde la esperanza dimanante del espíritu dinámico de la libertad" (Ibídem, p. 18).

La conclusió lògica d'aquest pensament, en paraules del propi autor, s'expressa com segueix:

La Carta de franquesa estaba pensada para este tipo de sociedad, un tanto de aluvión, aventurera, pragmática, de talante más bien resolutivo, sin proclividades nostálgicas - el que las sentía se marchaba-, embebida en la problemática de "su" presente para, desde la abnegación y la esperanza, tratar de forjarse con el esfuerzo necesario un futuro en una tierra nueva y 
arriesgada - como una especie de Far-West americano del XIX- administrada por hombres libres (Ibidem, p. 32).

En definitiva, el model d'en Quadrado amb algunes pinzellades pintoresques i l'aplicació del model "castellà" de reconquesta (Soto, 1984, pp.14-15), justificant les "llibertats" per la presència de la frontera i el caràcter predominantment municipal, on la Carta de Franquesa té un paper desmesurat.

L'emfiteusi, llavors, per a Santamaría no és un contracte de tipus feudal: malgrat assenyalar alguns vincles "feudals" de caire residual (fer el vi al celler senyorial, fer les escriptures davant del notari senyorial i l'acceptació de la seva jurisdicció civil), afirma que

en todo caso, las cláusulas < del contracte emfitèutic > no comprometían esencialment el status del enfiteuta como hombre libre, ni se le obligaba a prestar servicios personales adicionales o se restringía su libertad para resolver o rescindir el contrato conforme a derecho... (Ibídem, p. 53).

Tanmateix, la millor (o almenys la més extensa, coherent i documentada) exposició dels arguments del professor Santamaría es troba a Santamaría, $1990^{16}$. En aquesta voluminosa obra, l'autor fa una repassada als principals temes objecte del seu estudi, introduint un estudi sistemàtic de l'ECR, font documental que, al seu parer, referma les seves postures. Respecte la població autòctona, objecte de bona part de l'estudi, arriba a plantejar que

\begin{abstract}
no se comprende la escalada demográfica alcanzada en un siglo que, en tiempo histórico no es valorable como período cronológico dilatado, sin asumir la permanencia tras la conquista de un volumen cuantitativamente muy considerable - probablemente mayoritario- de exsarracenos mallorquines autóctonos cristianizados e integrados plenamente en la nueva sociedad cristiana (Ibídem, p. 248).
\end{abstract}

Tot això, naturalment, es produeix dins d'una "sociedad de connotaciones mayoritariamente burguesas", en la que l'emfiteusi atorga la cuasi propietat de la tinença a l'emfiteuta, de manera que "ello permite

\footnotetext{
${ }^{16}$ Vegeu també SANTAMARÍA 1981, 1987 i 1989.
} 
asumir la imagen de una sociedad rural mallorquina conformada por campesinos libres" (pp. 354-361).

Igualment, hom podria qualificar de bàsicament "neo-quadradianes" les aportacions de G. Alomar (Alomar, 1976 i 1978), encara que amb alguns elements originals respecte interpretacions anteriors.

Alomar no té problema per acceptar que el Repartiment és un fet fonamentalment "feudal" (Alomar, 1976, p. 28, nota 3), però això no té per a ell sinó una importància secundària, atès que, com ja hem vist abans per al cas de Santamaría, es mostra molt insistent en la decadència del feudalisme al segle XIII (Ibidem, pp. 36-37 i 39). En el cas concret de Mallorca, afirma l'autor, el repartiment "feudal" no determinaria l'estructura socioeconòmica ulterior, ja que en realitat es produirien no un sinó tres repartiments successius, de manera que l'estructura de la propietat no estaria definitivament instal·lada fins al tercer repartiment (Ibidem, p. 82), objecte de les Ordinacions de Jaume II: es tractaria, en definitiva, d'un procés "orgànic" de "democratització" paulatina, fins arribar a unes estructures despreocupadament qualificades de "socialistes" ("...socialistas, diríamos hoy", Ibídem, p. 60), introduïdes per tecnòcrates itinerants com ara Pere Sturz, i preocupació principal del programa polític de Jaume II. La hipòtesi de tres repartiments successius resulta una bona eina de treball aplicada a la investigació sobre el període, tot i que, de fet, seria el "segon repartiment" (entre el Llibre del Repartiment i les Ordinacions el que marcaria realment la colonització de 1 'illa. Un altre aspecte d'interès remarcat per Alomar consisteix en l'origen dels repobladors de Mallorca. A diferència del que resulta més comunament acceptat, Alomar remarca la importància dels elements occitans, foragitats de llur país per la repressió anticàtara (Alomar, 1978) ${ }^{17}$.

Però, juntament amb elements suggerents, hom hi troba importants desencerts, com ara els dissortats i fantasiosos intents de calcular la població mallorquina al segle XIII, sobretot de la part forana, a partir de la identificació d'alqueries i rahals (sense especificar-ne) amb les possessions del segle XIX (Alomar, 1976, pp. 10-11). El nombre total d'alqueries i rahals, extret de l'infortunat treball de J. Bisson (J. Bisson, 1967), és d'unes 1.000

\footnotetext{
${ }^{17}$ En el fons d'aquest plantejament hi ha, emperò, una bona dosi d'anticatalanisme. Independentment del fet de la presència (abundant) d'occitans $\mathrm{i}$ altres (aragonesos, italians), la major part de la repoblació és, com recentment ha palesat A. MAS (1994), catalana.
} 
explotacions, en comptes de les 1600 i escaig que en realitat hi havia ${ }^{18}$, de manera que qualsevol càlcul demogràfic resultarà necessàriament erroni. Però més erroni resulta, al meu parer, assimilar el poblament de les possessions de $1860 \mathrm{amb}$ el de les alqueries i rahals del segle XIII, particularment si ens referim a època islàmica:

Para los que, como yo, pertenencen a una familia de antigua raigambre mallorquina rural...estas explotaciones de cultivo que, con el nombre de possessions, en la década de 1920-1930 no eran sino las mismas alquerías o rafales de los moros... (Ibidem, p. 11).

Així, extrapolant dades d'un context social força diferent, l'autor arriba a la conclussió d'una mitjana de 12 persones per explotació-tipus de 6,4 Hes. Per últim, l'atribució de mil habitants com a mitjana als "núcleos urbanos del agro insular distintos de la Medina" ( $i$ ?) (Ibidem, p. 12) és pura especulació. En definitiva, l'únic que queda clar és que l'autor desconeix totalment l'estructura del món rural andalusí i que, com molts altres, ha caigut en el parany de considerar la història de Mallorca una pura conseqüència de la seva insularitat $i$, per tant, "immutabilitat illenca".

\section{El "TRENCAMENT" AMB LA INTERPRETACIÓ D'EN QUADRADO:}

a) Noves interpretacions del "feudalisme mediterrani" i de la "reconquesta" ibèrica

Les aportacions historiogràfiques més recents parteixen del supòsit de considerar la conquesta i colonització de Mallorca com a fenòmens feudals, trencant, així, amb el vell esquema quadradià posteriorment

\footnotetext{
${ }^{18} \mathrm{~J}$. Bisson utilitzà per al seu treball el Códice Latinoarábigo (CLA del Llibre del Repartiment, editat per J. Busquets (BUSQUETS, 1953). El CLA només conté una part de les donacions reials, la que va efectuar directament el rei als seus porcioners, però no la que va distribuir a les universitats $\mathrm{i}$ grans porcioners, com el Temple, de forma que inventaria unes 500 alqueries i rahals i no les més de 800 recullides a les versions completes i més conegudes del Llibre del Repartiment (Bofarull i Quadrado). Bisson calcula, així, un 17,5\% de terra conreada per al total de l'illa, de forma òbviament errònia. Alomar el segueix: "Según esto, la superficie cultivada en época musulmana representaría no más de un $17,50 \%$ de la total de la isla...Pero se apoya en datos documentales fidedignos y debemos dar por bueno este 17,5\%" (ALOMAR, 1976, p. 11). Un simple cop d'ull a Quadrado hauria bastat per a no donar per bo aquest $17,5 \%$.
} 
reinterpretat i readaptat de Mallorca com a societat no feudal, sense que s'hi donès una alternativa vàlida a aquesta "manca de feudalisme". Perquè la crítica més de fons que hom pot fer d'aquestes interpretacions és justament aquesta: si no es tracta d'una societat feudal, llavors, què és?. Una societat "moderna" i "democàtica"?

Una bona part de les argumentacions "no-feudals" que hem vist, en autors com Santamaría o Alomar, encaixen amb els esquemes desenvolupats per una classe d' "història econòmica" medieval, entesa bàsicament com a "història del comerç". La formulació més brillant a Espanya és la de J. Vicens Vives ${ }^{19}$, la seva aplicació més directa al cas de la història mallorquina seria la inclusió de les illes Balears dins d'una suposada "ruta de les illes", dissenyada pel poderòs lobby dels mercaders barcelonins, fent de la Corona un aliat gairebé sumís, i deixant molt en segón pla als senyors feudals. Així, ciutadans i mercaders serien l'element dirigent real a Mallorca (Piña Homs, 1977), i les lluites entre el regne de Mallorques i la Corona d'Aragó, lluites econòmiques entre els mercades mallorquins i els catalans. Malgrat la "modernitat" dels arguments, es poden encaixar perfectament en les tesis quadradianes, i axí ho fa Santamaría, quan parla d'"empresa comanditària" o de societat "precapitalista" (Vid. infra) en referir-se a la conquesta de Mallorca i la societat estructurada posteriorment, o, anant encara més lluny, quan parla d'un estat "talassocràtic", la supervivència del qual estaria en la seva poderosa flota mercantil, "la más importante del Mediterráneo después de la genovesa y la veneciana".

Tanmateix, en les fases inicials de l'expansió, el paper dels mercaders catalans per obrir mercats sembla haver estat sobrevalorada, com palesa M. Del Treppo (Del Treppo, 1976), i, en el cas de Mallorca, el comerç tampoc sembla haver estat ni de bon tros tan important com s'havia arribat a dir. A. Riera remarca el caràcter predominantment "passiu" d'aquest comerç, que tenia tant els greus problemes derivats de la forta competència de rivals més forts com els derivats de les limitacions d'una flota poc desenvolupada i insuficient:

Els mercaders balears, obligats a efectuar viatges curts $\mathrm{i}$ amb premura de temps, tendien a emprar vaixells d'escàs tonelatge, llenyes $\mathrm{i}$ barques (RIERA, 1979-1980, p. 127).

\footnotetext{
${ }^{19}$ Aquest paràgraf i següents són, com es veurà, tributaris de J. Portella.
} 
Si el cas de Mallorca no és aberrant, la societat mallorquina deuria ser molt semblant a les societats més properes de la Mediterrània Occidental, molt més a la de Catalunya que no pas a les ciutats italianes. Precisament una de les bases de l'argumentació d'una Mallorca no feudal rau en la particularitat dels feudalismes "mediterranis" o meridionals, amb gran presència de ciutats comercials (Itàlia) o estats forts (Castella), on el feudalisme de la Catalunya Vella resultaria exòtic. Aquesta argumentació, naturalment, es basa en la vella definició de feudalisme com a règim "feudovassallàtic", que alhora que jurídicament el defineix geogràficament "EntreLoire-et-Rhin".

Tanmateix, les opinions respecte el feudalisme mediterrani han anat evolucionant considerablement, de forma que a hores d'ara ja no es poden sostenir velles postures. Les conclusions del "Colloque" de l'"École Française de Rome" de l'any $1978^{20}$ Structures féodales et féodalisme dans l'Occident Méditerranéen van ésser en aquest sentit molt clares: en primer lloc, reafirmació del feudalisme català particularment, encara que no exclussivament: Bonnassie arriba a plantejar:

\footnotetext{
En définitive, on peut se demander s'il ne conviendrait pas d'inverser le postulat qui, partant d'un soi-disant modèle septentrional, déclarait "incomplètes" les féodalites méridionales: l'inachèvement ne serait pas à rechercher entre Loire et Rhin? (BONNASSIE, 1980, p. 46).
}

En segon lloc, diferents autors remarquen aspectes feudals fins llavors negligits tant a la França meridional ${ }^{21}$ com al nord de la Península Ibèrica (Pastor, 1980). L'aportació de R. Pastor és particularment important, atès que suposa una severa crítica a la interpretació tradicional imposada per Sánchez Albornoz, en que el "régimen concejil" aliat a la Corona era la millor garantia contra l'expansió del feudalisme a Castella. (No oblidem que, de fet, la interpretació tradicional del règim de franqueses de Mallorca coincideix en molts punts amb la interpretació tradicional del feudalisme castellà). El "reducte" del món no feudal a l'Europa occidental, Itàlia, va ser objecte de la major part de les aportacions a aquest "Colloque", tant pel que

\footnotetext{
${ }^{20}$ Encara que celebrat al 1978 , les actes del "Colloque" es van publicar al 1980 , i és citat per aquest any. N'hi ha una edició espanyola d'una selecció de comunicacions (PASTOR, 1984).

${ }^{21}$ Vegeu al citat "Colloque" particularment les aportacions de J.P. Poly, G. Giordanengo, Ch. Higounet, M. Gramain i E. Magnou-Nortier.
} 
fa als estats pontificis com a l'Itàlia del nord i del sud (particularment interessant el cas de la colonització de Sicília, amb la comuniciació de J. Richard), o un conjunt de temes tan interessants com les relacions entre el mon urbà i el feudalisme. De gairebé totes aquestes aportacions hom treu la conseqüència d'una Itàlia molt més feudalitzada del que fa relativament poc temps hom hi pensava, on el teixit urbà, per exemple, recolza (i és recolzat) per les estructures feudals, molt lluny de les radicals divisions estructurals que feien dels mons urbà i rural els representants (antagònics, és clar) del capitalisme i del feudalisme ${ }^{22}$.

Posteriorment, s'ha arribat fins i tot a considerar el feudalisme italià com gairebé modèl-lic, de manera que el incastellamento estudiat per Toubert (1973 i 1990) esdevé ja no un fenomen estrany i perifèric, sinó el "model" d'estudi de la major part de les societats feudals mediterrànies. De fet, els dos colo.loquis que han tingut lloc recentment a Girona ${ }^{23}$ i Roma ${ }^{24}$ partien d'aquests pressupòsits. L'incastellamento té dues aventatges per a l'estudi de la formació del feudalisme: per una banda, permet incorporar els avenços de les tècniques arqueològiques, trencant la dependència exclussiva d'una documentació escrita que només reflecteix l'àmbit senyorial que la va generar; per una altra, permet la comparació amb altres zones mediterrànies contemporànies però alienes al sistema feudal, com ara les regions andalusines.

Si les opinions respecte el "feudalisme mediterrani" o "meridional" s'han anat modificant resulta perquè allò que s'ha modificat sensiblement és l'opinió respecte el feudalisme en si. No és que s'hagi conclòs la polèmica entre partidaris de distingir entre un "feudalisme" restringit com a règim vassallàtic $i$ un règim senyorial, seguint el corrent juridicista tradicional de Ganshoff o Boutruche, per una banda, i els partidaris del "mode de produccció feudal" marxista, per l'altra. Més aviat succeeix que intentar explicar globalment la societat medieval europea duu a unir de forma

\footnotetext{
${ }^{22}$ On, en canvi, no sembla haver-hi trets de feudalisme és fora del mon occidental. Les aportacions al "Colloque" sobre Bizanci i l'Islam, en particular sobre al-Andalus oriental (GUICHARD, 1980), palesen uns sistemes socio-econòmics força diferents dels del Mediterrani nord-occidental cristià, al qual, amb tota propietat, hom pot qualificar de "feudal".

${ }^{23}$ Reunió científica sobre "L'incastellamento', vint anys després", celebrada a la Universitat de Girona el 26 i 27 de novembre de 1992.

24"L'incastellamento: confronto fra società feudale e non feudale nel Mediterraneo occidentale", Roma, 5-7 de maig de 1994.
} 
indestriable les relacions feudovassallàtics $\mathrm{i}$ el senyoriu, com palesa per exemple J. Portella basant-se en R. Bonnassie:

\begin{abstract}
S'accepta, doncs, que el camperolat es trobava sotmès a la dominació o senyoria de la classe nobiliària, però no pas que el poder senyorial -amb l'amenaça permanent dels cavallers armats- fos la peça clau de les relacions socials forjades entorn a la terra, i, per tant, dels dominis i rendes senyorials. Pel contrari, exceptuant la tributació suplementària derivades de concessions reials de sobirania, les rendes de la terra pròpiament dites s'haurien pactat lliurement entre particulars, al marge de la feudalitat i com a justa retribució per l'usdefruit o possessió d'unes hipotètiques propietats senyorials.
\end{abstract}

Més endevant veurem que aquest tipus de definició del règim senyorial no s'ajusta a les condicions jurídiques dels establiments medievals. En canvi, l'estudi d'aquests establiments ens demostrarà una vegada més que

\begin{abstract}
el feudalismo, en el sentido europeo y medieval del término, no era más que un aspecto del feudalismo considerado en su sentido más amplio. Porque ¿qué era en realidad aquel feudo que le confería su existencia? Era un conjunto de bienes y de rentas: los bienes consistían generalmente en tierras donde trabajaban campesinos, y el producto de su trabajo era el que daba valor al feudo: las rentas eran impuestos (banales) o los tributos pagados por aquellos mismos campesinos. Por ello, estudiar la historia del feudo olvidando la punción nobiliaria equivale a estudiar una abstracción (PORTELLA, 1985-1986, pp .337-338) ${ }^{25}$
\end{abstract}

D'altra banda, com assenyala $\mathrm{M}$. Barceló, el "règim senyorial" dels historiadors clàssics s'assembla bastant al "feudalisme" de la historiografia marxista:

La fácil reconciliación pasa sencillamente por permitir que el término feudalismo no limite su contenido a su propio origen institucional - por otra parte nada alejado de las formas "señoriales" de expropiación de la producción campesina $-\mathrm{y}$ pueda designar al conjunto de relaciones sociales que se derivan del dominio, institucionalmente refrendado, que una clase social ejerce sobre el campesinado, cuya manifestación es la captación de parte de la producción en forma de renta (BARCELó, 1988, pp. 32-34).

\footnotetext{
${ }^{25}$ Les paraules de Bonnassie procedeixen de BoNNASSIE, 1983, pp. 94-95.
} 
La "societat feudal", llavors, en una cada vegada més acceptada accepció integrada que sens dubte deu molt als ja antics però mai desfasats estudis de Marc Bloch, seria aquella en la qual els vincles estrictament "feudals" o "feudovassallàtics" determinen el funcionament dels altres elements que, naturalment, també existeixen. Així, encara que còmoda, la distinció entre "feudalismes" i "feudalitats" és un intent conciliador estèril, sols justificat per l'aspresa de la polèmica i l'enuig que la seva durada comporta. Sembla, llavors, necessari, remarcar el pes que el feudalisme jurídic té dins del desenvolupament del feudalisme en general, entès com a "sistema"26, ja que és normalment la forma en que es desenrotllen les relacions entre les classes dominants, de manera que fins i tot quan s'adopten fórmules jurídiques noves (la recepció del dret romà, etc.), aquestes el que fan és legitimar per escrit i perfeccionar els drets derivats de la relació estrictament feudal ${ }^{27}$.

Tot el que s'acaba d'exposar es veu clarament amb l'evolució del "feudalisme ibèric" i la seva expansió territorial o "reconquesta" des del punt de vista historiogràfic. No és pas la meva intenció fer una repassada, ni que sigui breu, a la bibliografia sobre aquest tema, atès que és considerablement voluminosa (almenys), però sí caldra afegir-hi algunes paraules.

Fins a temps relativament molt recents, el model ideològic aplicable a l'estudi del feudalisme ibèric i la seva expansió oscil-lava entre el juridicisme clàssic i el que podem qualificar de "nacionalisme històric" $o$, millor encara, "nacionalismes històrics". En el cas castellà, o si es preferiex, "espanyol", García de Valdeavellano i Sánchez Albornoz encunyen un model consistent en la doble acceptació del feudalisme clàssic feudovassallàtic i l'excepcionalitat "nacional" del cas castellà-espanyol que en conseqüència, naturalment, no pot exportar un sistema feudal. En el cas català, s'accepta

\footnotetext{
${ }^{26}$ Això és el proposava P. Toubert al discurs inaugural de l'esmentat "Colloque" de l'Escola Francesa de Roma on, d'una banda, aconsella la utilització de "feudalisme" sense distincions "ocioses": "...il me paraît utile d'affirmer dès le départ qu'en parlant de féodalisme, nous entendons dire que le système économique et sociale de l'Europe médiévale est assez caracterisé et reconnaissable dans ses lois 'évolution spécifiques pour requérir l'usage d'un mot qui permette de distinguer ce système de ceux que l'ont précedé ou suivi. Comme l'écrivait trés récemment à ce propos notre collègue Hilton, "éviter le mot féodalisme nous obligerait à en inventer un autre qui devrait à son tour comprendre son acception à la fois la féodalité, et la seigneurie"; je préciserais très volontiers pour ma part qui dévrait intégrer, a la fois la féodalité comme système d'institutions et l'ensemble des structures de production et de profit propres à l'époque féodale" (TOUBERT, 1978, p. 3).

${ }^{27}$ Vegeu, en aquest sentit, C. BATET i R. SOTO (1997), i per a una teorització del paper central de la renda feudal en el procés del treball pagès, BARCELó (1988 i 1995).
} 
l'existència d'un feudalisme jurídic molt clar per a la Catalunya Vella, però aquesta acceptació serveix molt més per a remarcar un fet "nacional", diferenciador d'un model espanyol o castellà, que no pas com a punt de partida per al plantejament de problemes històrics en profunditat. Això queda clar amb la facilitat amb la qual els historiadors catalans renuncien a plantejar-se la "manca de feudalisme" a les zones d'expansió catalana ${ }^{28}$.

El model explicatiu imperant a l'hora d'interpretar la "reconquesta", tant a zones de conquesta castellana com a zones de conquesta catalanoaragoneses seria, llavors, el "castellà" o "espanyol" de Sánchez Albornoz, que serviria tant per explicar la conquesta i colonització d'Andalusia com la de Mallorca, que és el que de fet hem vist.

Ara bé, les coses a l'àmbit de la historiografia peninsular a hores d'ara també fa anys que semblen anar-se modificant. Naturalment, encara hi ha qui defensa velles posicions. Així, M. González (González, 1990), rera rebutjar

la validez o no en el ámbito regional... de la teoría que presenta las operaciones de conquista y, por supuesto, de sus efectos repobladoreses, como una forma de "agresión feudal" y camino para la reproducción del sistema mismo

nega totalment la formació d'una societat feudal a l'Andalusia bètica, el que hauria motivat l'emigració de nobles o la formació d'una nova noblesa, i afegeix:

¿Qué factores impidieron que la "marea" feudal cubriese también Andalucía? Podrían alegarse algunos, tales como la proximidad de la frontera; el predominio de los grandes concejos de realengo; la propia voluntad política de los reyes. Pero el fundamento era la propia contextura de la sociedad, integrada por hombres libres, propietarios todos ellos de tierras Las relaciones entre los grupos dominantes y los menos favorecidos se establecen no a través de un entramado de dependencias y de usos más o menos onerosos de tipo feudal, sino desde la libertad jurídica. Y desde esta perspectiva sólo cabían relaciones contractuales, que se extienden incluso a las relaciones señor-vasallo...Por otra parte, como han puesto de relieve las investigaciones realizadas hasta el momento, el régimen señorial andaluz se sustentaba sobre presupuestos un tanto atípicos. De entrada, las rentas señoriales eran muy poco feudales. El comercio, las actividades pesqueras,

${ }^{28}$ C. BATET i R. SOTO (1997), p. 232 i ss. 


\begin{abstract}
la exportación de aceite, jabón, trigo y vino les proporcionaban, directa o indirectamente, saneados ingresos. Eran, sin duda, grandes propietarios. Pero no siempre - diría que de forma muy excepcional- explotaban directamente sus grandes cortijos y dehesas. La explotación directa sólo es observable en el caso de cultivos altamente especulativos como el olivar (GONZÁLEZ, 1990. p. 116-117).
\end{abstract}

L'autor continua remarcant les diferències entre els jornalers (homes lliures) i els serfs, i acaba dient

Y es que la gran tragedia de Andalucía fue que en ella no se implantó un feudalismo pleno, y sí, en cambio, un sistema tan moderno y tan fuera de época que estaba por ello mismo condenado a convertirse en poco tiempo en una simple caricatura de sí mismo (Ibídem).

Com es pot veure, les coincidències entre González i Santamaría són més que remarcables, fins i tot a l'hora de culpar del fracàs de llurs respectives societats al fet d'ésser d'una "modernitat" que les condemnava al fracàs en la seva època.

Tanmateix, les actuals tendències d'investigació sobre la conquesta i repoblament de zones com Andalusia, Castella meridional i València semblen força diferents, i si hi ha una cosa que tothom accepta, amb més o menys matisos, és que es tracta de fenòmens de caire feudal. Així, A. Barrios assenyala que

la conquista de la rica taifa de Toledo... ha de ser entendida necesariamente como el resultado de una clásica agresión feudal, motivada por la coincidencia de intereses entre la aristocracia y la monarquía feudales (BARRIOS, 1985).

A zones i èpoques molt més properes a la conquesta de Mallorca també s'hi accepten els models feudals de conquesta i repoblació. En el cas de València, els estudis d'A. Furió, F. Garcia, E. Guinot i J. Torró, per exemple, parteixen del presupòsit d'una conquesta motivada per l'agressió feudal, ja que "la guerra és el mitjà més ràpid i racional d'augmentar la riquesa de la classe dominant al mode de producció feudal" (Furió \& García, 1983, p. 34), però no creant grans unitats d'explotació senyorial, sinó mitjançant "la configuració d'uns dominis no compactes territorialment sinó dispersos en una àmplia geografia" (Ibídem p. 34), tal com caracteritza al feudalisme G. Bois (Bois, 1980). Les formes d'establiment tant senyorials 
com reials estarien basades en l'emfiteusi (com a Mallorca) i no en la servitut, però els autors hi adverteixen que

No podem, tanmateix, reduir la servitut a una qualitat jurídica, puix cal entendre-la com a una relació de poder i domini senyorial front al camperol garantida per una coerció extraeconòmica. La subordinació del pagès a condicions de producció d'explotació, es tracte jurídicament d'un home lliure o no, crea per sí mateixa condicions de dependència econòmica. És a dir, no és necessari suposar una condició personal servil per arribar a les relacions reals de servitud, no hi cal suposar la subordinació jurídica de l'individu...Aquesta relació de subordinació i dependència es concretà al País Valencià fonamentalment sota la fòrmula de l'emfiteusi.

Amb ella, el senyor, que es reservava el domini directe, cedia al camperolat el domini útil d'una porció de terra, susceptible de ser venuda, alienada $\mathrm{i}$ de disposar-ne en plena facultat, que constituirà la base de la tinença camperola. El pagès, per la seua banda, estava obligat al pagament d'un cens anual bé d'una part de la producció o bé d'un impost fix en metàl-lic. L'emfiteusi, però, no pot deslligar-se del senyoriu on s'insereix i, per tant, de la jurisdicció inherent (mer i mixt imperi, o ambdòs), per la qual cosa, al marge d'una relació estrictament econòmica, se n'hi prefigura una altra de dominació política i jurisdiccional (i indubtablement ideològica, mitjançant uns altres elements existents al senyoriu, com ara la parròquia). La relació "contractual" no és, doncs, consensuada entre iguals, sinó de poder i domini dels senyors (FURIÓ \& GARCÍA, p. 37).

\section{b) La història de Mallorca subvertida: Mayurqa com a punt de referència}

Realment, una reinterpretació no "neoquadradiana" de la conquesta i colonització de Mallorca implica l'aplicació de models historiogràfics diferents als tradicionals aplicats per la historiografia que he comentat abans, però també (i potser en una mida més considerable) de la revaloració de la societat musulmana. Això suposaria una mena de subversió dels models tradicionals, que partint sempre de l'òptica de la societat conqueridora, només veurien en la societat musulmana un "niu de pirates" perfectament susceptible de ser anorreat (Quadrado, Santamaria, etc.), justificant-se l'acte en sí mateix. Interpretacions més recents (J. Bisson, Alomar, etc.) acceptarien un cert nivell de desenvolupament de l'agricultura i la societat musulmanes, però al cost de plantejar quelcom d'igualment estèril per a la comparació d'àmbdues societats (anterior i posterior a la conquesta), com ara el "mite" de la "immutabilitat illenca". 
El 1978, M. Barceló publicà un article sobre problemes d'història agrària suggerits per un text del geògraf al-Zuhrîn ${ }^{29}$, que suposà un gir copernicà sobre la interpretació tradicional, "normal" o quadradiana de la història de Mallorca, i que acabaria tenint conseqüències molt més pregones que ara això. D'entrada, el replantejament de la història de la Mallorca musulmana (Mayûrqa) obligà a reconsiderar també la història posterior a la conquesta feudal i, en definitiva, la pròpia societat feudal. Això consistia en veure la societat mallorquina-feudal i el feudalisme, en general, des de "fora", invertint els termes habituals, i, tot subvertint el punt de vista històric, aportava perspectives noves i sorprenentes. Barceló es plantejava com a hipòtesi de treball central la d'un fort canvi a l'estructura productiva de Mayûrqa a rel de la conquesta catalana: és clar que l'illa productora de cotò i importadora d'oli descrita per al-Zuhrî poc o res s'assemblava a la Mallorca de la Baixa Edat MItjana o de l'Edat Moderna.

\begin{abstract}
La conquesta catalana no és equiparable a la musulmana. No són dos moments en un mateix procés històric. La conquesta catalana imposa una ruptura gairebé total, en el sentit que liquida la formació social anterior amb un gest violent, ràpid i decisiu; encara que cada vegada sigui més àmplia i profunda la documentació sobre el sector musulmà autòcton (lliure o/i esclavitzat), l'ordenació social de la producció i de la reproducció de la nova formació social es fa a partir dels conqueridors. No és un problema o un joc de xifres de catalans i musulmans, sinó de domini, d'estructuració. No hi ha, doncs, un passat musulmà de Mallorca. Entre el 1229 i el 1231 comença la història de la societat mallorquina; comença el passat d'avui: una conquesta $\mathrm{i}$ una colonització que genera immediatament tota una sèrie de problemes i contradiccions que es revelen insolubles per als conqueridors mateix i que, a més llarg termini, resulten haver condicionat fortament el procés històric mallorquí en el que té de més específic, almenys fins a I'època contemporània: un sector esclau anormalment ampli (segles XIII$\mathrm{XV}$ ), una desfeta a aclaparadora, total, de les revoltes pageses (segles XV$\mathrm{XVI}$ ) que permet una progressiva sobreexplotació i un empobriment progressiu de la pagesia (formació d'un llarg sector de jornalers), un domini inflexible dels grans possessors de la terra $\mathrm{i}$ una hegemonia rigorosa dels mecanismes religiosos de control social. En aquest sentit, fa falta plantejarse la qüestió més general de l'imperialisme feudal com a fenòmen qualitiativament distint de l'imperialisme arcaic (BARCELó, 1984, p. 44).
\end{abstract}

\footnotetext{
${ }^{29}$ Citat indistintament com a BARCELÓ, 1975 i BARCELÓ, 1984. (L’article va aparéixer a "Recerques", 8 l'any 1078, però va ser reeditat a la compilació BARCELó, 1984).
} 
D'altra banda, els treballs més importants de P. Guichard (Guichard, 1976 i 1977) sobre l'estructura social de Sharq al-Andalus introduien també noves hipòtesis sobre la intensitat del poblament berber en aquesta regió, alhora que incidien en la importància dels elements tribals i clànics d'aquest tipus de poblament. Un bon camí per a acabar amb la recurrent i estèril discussió sobre "feudalisme àrabo-espanyol" (!!!) i mossàrabs... ${ }^{30}$.

Les hipòtesis estaven ben plantejades, i s'obrien camins novedosos. L'únic problema era el de trobar les fonts d'estudi, ja que apart de l'esmentada descripció d'al-Zuhrî, les cròniques musulmanes poc o res podien aportar a un estudi econòmic i social sobre les Illes Orientals. Allò que no existia enlloc era res de semblant a una documentació d'arxiu com la generada per les societats feudals europees, de forma que va esdevenir imprescindible l'estudi de fonts documentals "indirectes", com són totes les sèries documentals catalanes més o menys properes a la conquesta. En primer lloc, les distintes versions del Llibre del Repartiment es revelaren com a una font esplèndida per a l'anàlisi socioeconòmica de Mayûrqa. En segon lloc, els registres del segle XIII continguts a l'ARM, particularment l'ECR, serviren inicialment de bon complement a les deficiències i omissions del Repartiment.

La investigació sobre aquestes fonts documentals va prendre una doble direcció: per una banda, la riquesa del Repartiment i dels altres documents va ésser aprofitada en una llarga sèrie d'estudis sobre toponímia, realitzats fonamentalment per A. Poveda i el mateix M. Barceló.

Els estudis de A. Poveda (Poveda, 1978 i 1987, sobretot) demostren per a les Illes Orientals una estructura social que no difereix gaire de la que per a la resta de Sharq al-Andalus proposava P. Guichard: poblament agrupat en alqueries i rahals de tipus fonamentalment tribal i clànic, amb un clar predomini de l'element berber ${ }^{31}$. La fiabilitat d'aquests estudis resulta difícilment superable, ja que es basen en repertoris toponímics que cobreixen la totalitat de cada una de les illes. Un bon nombre de topòmims va ésser localitzat geogràficament, el que va fer possible a l'autor d'extreure

\footnotetext{
${ }^{30}$ Mossàrabs que, per exemple, Santamaría encara s'entesta a trobar a Mallorca (SANTAMARíA, 1990).

${ }^{31} \mathrm{El}$ total de topònims berbers és del $82,28 \%$ per a tot l'arxipèlag, amb un màxim a Manûrqa $(100 \%)$ i un mínim a Yâbisa $(58,33 \%)$, mentre que per a Mayûrqa és del $84,74 \%$. El nombre de topònims tribals i clànics, en BENI, és del 23,06\% globalment, repartits de la següent manera: Mayûrqa, 30,17\%, Manûrqa, 20\%, Yâbisa, 40,80\%.
} 
conclusions generals i particulars de l'estratègia de les comunitats rurals en l'ocupaciò de l'espai i la seva distribució. Per altra banda, una acurada i extensa anàlisi estadística sobre les dades numèriques (extensions superficials) del Repartiment li va permetre concloure que hi existia una correlació entre els topònims tribals i clànics i l'espai que ocupen, manifestació evident del valor essencial i orgànic que degueren teniraquestes estructures de parentiu a la formació social mayurquina.

L'any 1978 jo mateix vaig presentar la Memòria de Llicenciatura l'objectiu de la qual era l'estructura agrària de Mayûrqa (Soto, 1978) fonamentalment. Es tractava d'un estudi documental, utilitzant les mateixes fonts de l'ECR i del Repartiment, en el qual hom pretenia analitzar l'agricultura de l'època musulmana a partir de testimoniatges documentals una mica posteriors i poc o gens descriptius, ja que la majoria dels documents eren establiments o compravendes. De tota manera, algun dels resultats d'aquell ja molt llunyà treball era sorprenent, com la presència d'un policultiu bastant ben integrat de vinya, conreus arborícoles i regadiu. La vinya havia estat clarament introduïda a partir de la conquesta, ja que molts del esments documentals de vinya eren ordres explícites per a plantar-la, de manera que allò que més cridava l'atenció era la importància del regadiu. La situació de policultiu i petit regadiu, d'altra banda, resultava altament coherent amb el panorama d'explotacions de tipus tribal i clànic ja esmentat, i que resultava general en distintes zones del Magreb.

Les fonts documentals escrites encara van permetre d'afegir alguns elements d'interès al coneixement de la societat andalusina de les Illes, com ara el de la composició "racial" de mayurquins i manurquins, deduit a través de les vendes d'esclaus posteriors a les respectives conquestes (Soto, 1981 i Jené, 1985-1986). Fins a quin punt la mostra recollida en aquesta documentació fos representativa de la població indígena era quelcom possiblement discutible, però no deixa de sorprendre que un percentatge tan alt d'ella fos descrit com a "no blanc" (negres i "lauros") a les dues illes ${ }^{32}$.

Aquest aspecte, ensems amb la forta evidència documental de mesquites rurals a Mayûrqa (Soto, 1979) permet dubtar amb fonament més que raonable de l'existència de col-lectius "mossàrabs" a les Illes Orientals, sempre i quan el confús terme "mossàrab" sigui usat amb propietat i no com

\footnotetext{
${ }^{32}$ Els percentatges respectius són: per a Mallorca, $74,27 \%$ blancs, $13,59 \%$ negres i $12,13 \%$ "lauros". Per a Menorca, 32\% blancs, $45 \%$ negres i $23 \%$ "lauros".
} 
a laxe sinònim de qualsevol grup de religió cristiana i de procedència exterior a les illes (mercenaris "francs", mercaders italians, etc.).

Els sistemes de regadiu van constituir a partir de llavors el punt de partença de varis estudis. La capacitat hidrològica de Mallorca no permet corrents d'aigua constants, i les fonts naturals són escasses, així que l'origen d'aquest hidraulisme documentalment palesat havia d'ésser diferent del gran hidraulisme fluvial que va donar origen a les grans hortes de l'Ebre o de Sharq al-Andalus.

M. Barceló va plantejar ja al 1978 la possibilitat, que per aquell moment només es podia recolzar en alguna dada toponímica, de l'existència de qanât(s) a Mayûrqa, de forma que el regadiu mayurquí es basaria, fonamentalment, en aquestes captacions subterrànies d'aigua d'origen iranià, extendides cap al Magreb per tècnics itinerants o muqanî, tot seguint unes tècniques molt precises ${ }^{33}$; però en un terreny tan concret com el dels sistemes de regadiu, la documentació escrita aviat hauria de deixar pas a la prospecció de camp.

M.A. Carbonero va encetar amb la seva memòria de llicenciatura sobre el sistema de regadiu integrat (ma'jil) de Banyalbufar una sèrie de treballs de camp sobre l'hidraulisme agrari mallorquí (Carbonero, 1982, 1984 i 1988. El ma'jil de Banyalbufar integra una captació d'aigües del tipus qanât i un sistema de sèquies per al repartiment col·lectiu de l'aigua en una sèrie de terrasses abancalades provistes de safarejos. El sistema comptava també, naturalment, amb un o varis molins.

Els darrers cinc anys, successives campanyes de prospecció arqueològica dirigides per $\mathrm{M}$. Barceló s'han orientat cap a diversos problemes de l'hidraulisme mallorquí, intentant determinar, sobretot, els orígens d'aquest. Com assenyala el mateix M. Barceló, i malgrat que un sistema de regadiu és quelcom subjecte a modificacions pels diferents ocupants d'aquest en diferents èpoques

\footnotetext{
...cuanto mayor sea el sistema más extenso será el calendario de su construcción. Pero ello nada dice de cómo ha sido concebido y diseñado. Esta cuestión es decisiva no sólo para comprender cómo son creados los espacios irrigados y las posibilidades de crecimiento que tienen, sino también para estimar y evaluar las condiciones sociales y técnicas, es decir,
}

\footnotetext{
Karajî.

${ }^{33}$ Veure particularment R. MARTí, 1986, dedicat al tractat de construcció de qanât(s) de al-
} 
las soluciones de continuidad precisas, en que la unidad tecnológica de un sistema puede ser utiizada, sin mengua de su eficiencia, por una sociedad distinta a la de sus creadores. Todo sistema hidráulico, cualquiera que sea su grado de complejidad, ha sido concebidoy diseñado en su estructura fundamental desde el principio (BARCELó ET ALII, 1988, p. 244).

La publicació de Les aigües cercades (1986), en la que col-laboraren juntament amb M. Barceló, G. Rosselló Bordoy, M.A. Carbonero i R. Martí, va suposar una important contribució a l'estudi d'aquest tipus de captació d'aigües, molt més abundant a l'illa d'allò que molts, en un principi, podien haver suposat. El llibre no era un simple catàleg de qanât(s) localitzats i descrits a diferents indrets de l'illa, sinó que intentava determinar amb exactitu la qüestió del seu origen i establir-ne una tipologia.

L'estudi dels qanâts va donar origen a un tipus d'estudi basat en la confluència d'arqueologia extensiva i treball documental. Les fonts documentals escrites, generades en un context social molt concret (el de l'esfera de poder feudal) molt poc podien explicar sobre l'objecte d'estudi real, que eren les formacions socials de pagesos. D'aquesta manera, cada cop més, es va evidenciar la necessitat d'estudiar aquests a través de les seves pròpies restes, que no eren altres que els espais conreats. L'arqueologia extensiva agrària no era cap novetat a altres països, però sí a l'àmbit estatal espanyol. El treball de H. Kirchner (1994) va permetre el coneixement dels perímetres iirigats dels assentaments de les valls de la Serralada nord i el Raïguer, mentre que el treball de M. Barceló et alii (1995) sobre l'antic territori de Felanitx feia el propi amb els assentaments del migjorn. De fet, era la primera vegada que hom disposava de coneixements reals d'aquests assentaments, ja que, com s'ha dit, les notícies documentals, sobre les quals es basaven els coneixements convencionals, eren molt esbiaixa$\operatorname{des}^{34}$.

c) Cap a una nova interpretació de la conquesta $i$ colonització de Mallorca

A partir d'aquestes premises, J. Portella plantejà en reiterades ocasions el problema de la conquesta i colonització de Mallorca. L'autor

\footnotetext{
${ }^{34}$ Per exemple, la documentació escrita tendeix a magnificar el paper de la vinya, mentre que el regadiu és poc esmentat.
} 
proposa un esquema interpretatiu de la historiografia al respecte, criticant particularment el concepte de Mallorca com a terra de llibertats i societat no feudal, palesant la funcionalitat "ideològica" de caire conservador d'aquestes interpretacions. Si Mallorca inicia la seva història ${ }^{35}$ amb tan venturoses circumstàncies, ¿per què el desastre posterior, que acabaria conduint a la revolta forana, per exemple? L'especialització bladera de l'illa, a partir de la conquesta, ensems amb l'estructura social introduïda pels catalans, hi tindrien molt a veure, molt més que no pas les circumstàncies "climatològiques":

Curiosament la historiografia oficial mallorquina ha mostrat el mateix grau d'alienació que els contemporanis, sovint dedicats a fer rogatives "propluvia", perquè presenta sistemàticament les violentes fluctuacions de les collites i la insuficiència estructural de gra com uns fenòmens deslligats de la societat, naturals, socials només en els seus efectes...Perquè les variacions climatològiques apareixen com a causa de la penúria quan l'extracció de l'excedent per part de l'amo o de l'Estat és tan intensa que situa al pagès a nivell de pura subsistència, sense possibilitat de millorar les seves tècniques $\mathrm{i}$ acréixer el rendiment de les terres. Aleshores l'escassetat subjuga tota la formació social (PORTELLA, 1983, p. 126).

Portella assenyala que el feudalisme "efectiu" aplicat a Mallorca ultrapassa els límits del règim senyorial i l' "ecofeudalisme", rastrejant àdhuc indicis d'aplicació de feudalisme jurídic o feudovassallàtic, tot consignant aportacions recents de diferents autors:

\begin{abstract}
Aunque para solucionar adecuadamente el problema historiográfico del feudalismo en Mallorca deberíamos contar con investigaciones minuciosas sobre la aplicación efectiva - no supuesta- de los "Usatges", la estructura agraria, etc..., las aportaciones recientes de A. Le Senne (1981), Pedro de Montaner (1978), J. Suau y I. Moll (1979) ya permiten entrever la existencia de un orden social feudal. Los ejemplos podrían multiplicarse, pero consideramos suficientemente expresivas algunas de las reseñas documentales incluídas en la tesis de licenciatura de A. Le Senne:

-En fecha 8 de junio de 1241, Juan Núñez presta homenaje y juramento de fidelidad a Arnaldo de Togores, a quien reconoce como dominus..." (PoRTELLA, 1984, p. 143).
\end{abstract}

\footnotetext{
${ }^{35} \mathrm{Ja}$ que, tal com assenyala, "Tradicionalment la historiografia oficial castellanista i catalanista han considerat - per definició, és clar - que la història de Mallorca començava l'any 1229 amb la conquesta catalana" (PORTELLA, 1983, p. 119).
} 
Aquest feudalisme no es tradueix en servitud jurídica, certament (Ibídem, pp. 143-144). però en realitat aquest lligam "jurídic" no és necessari, atès que el sistema d'establiment emfitèutic assegura la dependència camperola perfectament, sobretot si s'entén correctament i no com a emfiteusi a la romana. Portella considera que el Llibre del Repartiment demostrava l'existència d'un grup considerable de grans propietaris:

Però després ens hem adonat que la qüestió estava mal plantejada, perquè de fet no es tracta de propietaris ${ }^{36}$ sinó de dominis senyorials dels magnats $\mathrm{i}$ d'alous francs (lliures de càrregues censals) concedits a les ciutats $\mathrm{i}$ els particulars que havien participat en la conquesta. Molts d'aquests alous, per cert, s'acabarien constituïnt igualment en dominis senyorials, anomenats cavalleries. I fou des de les diverses senyories que es va procedir a l'establiment de nous pobladors a l'illa (PORTELLA, 1985-1986, p. 339).

L'argumentació de J. Portella és, al meu parer, força sòlida, ja que en definitiva es basa en tres punts difícilment contestables: en primer lloc, la utilització de "feudalisme" en un sentit ampli i no restringit. En segon lloc, l'existència a Mallorca de porcions nobiliàries (les "cavalleries") sotmeses a dret feudal encara que sense mals usos, on l'aplicació dels Usatges sembla provada i on les relacions plenament feudals (juraments de fidelitat, vassallatge, etc.) són normals i no excepcionals. Per últim, el paper importantíssim de l'establiment a cens/emfiteusi a l'hora de definir les relacions entre senyors i pagesos, tot i deixant ben clar el paper "feudal" d'aquesta emfiteusi. El funcionament d'aquestes cavalleries, que no són sinó "unitats de feu", dóna lloc a un feudalsime "de llibre" (Portella, 1994)

Altres investigacions han intentat seguir per camins semblants, intentant aplicar aquests esquemes a la rica documentació mallorquina dels segles XIII i XIV.

A. Rodríguez (Rodríguez, 1982 1985-1986 i 1994) ha estudiat bàsicament els establiments emfitèutics a la porció del Temple a Pollença, deixant ben clar que l'emfiteusi és un instrument de sotmetiment de la pagesia a unes exaccions cada cop més altes, sobretot en el període de repoblació. La tendència a la parcel·lació de les antigues explotacions andalusines i l'aparició d'un grup de senyors mitjancers, que sotsestableixen les terres que

\footnotetext{
${ }^{36}$ L'autor basa la primera part de la seva argumentació precisament en la inexistència de propietat tal com es coneix dins del sistema de tinença de terres capitalista, dins d'un sistema feudal, on més aviat cal parlar de drets sobre les terres (PORTELLA, 1985-86).
} 
segurament reberen en temps molt immediats a la conquesta, i que constitueixen una classe emergent, juntament amb els nobles que acabarien al front de les cavalleries, són dues conclusions ben fonamentades d'aquest estudis, alhora que donen pautes per a estudis posteriors.

Des del treball de J. Portella sobre el procés d'establiments basats en l'emfiteusi ${ }^{37}$ fins als més recents de A. Mas $^{38}$ passant pels meus propis $^{39}$, tots els estudis sobre la repoblació i colonització del territori mallorquí més recents han servit per a dibuixar la complexitat d'aquest fenòmen. Malgrat les limitacions que la documentació escrita imposava a aquests treballs $\mathrm{s}^{40}$, han contribuït a explicar les pautes del repoblament. Tot i així, documentalment també es poden inferir coses importants, com per exemple sobre el subpoblament ${ }^{41}$ i l'expansió de la ramaderia ${ }^{42}$. Ara bé, la documentació escrita té uns límits que queden superats pel treball de camp, o arqueologia extensiva. Els exemples més representatius d'això el constitueixen, bàsicament, els treballs de $\mathrm{H}$. Kirchner sobre l'agricultura irrigada andalusina de les zones del Raïguer i la Serralada, i el treball de M. Barceló i H. Kirchner sobre el territori de Felanitx anteriorment esmentats.

De tots els treballs citats en surten dos tipus de "repoblament" relativament diferents: l'un, el més conegut per ser el més estudiat (Rodríguez, 1982, 1985-1986 i 1994, Soto, 1991, Kirchner, 1994) en torn a una vall irrigada on s'instal-la una vila, un primer cercle de terres de regadiu i, posteriorment, alqueries de muntanya (deixem a banda l'exemple d'Inca i de la rodalia de Ciutat, que podriem qualificar de "periurbans"). Aquests exemples corresponen a zones de muntanya situades al Raïguer i/o

\footnotetext{
${ }^{37}$ PORTELLA, 1985-86. En aquest treball es destaca el paper "organitzador" de l'emfiteusi La demanda de renda feudal és aqui la que genera la lògica de l'ocupació de l'espai.

${ }^{38}$ Antoni MAS (1994) palesa de forma convincent $\mathrm{i}$ ben documentada que el procés d'immigració estava lluny d'ésser tancat, almenys, fins a mitjan segle XIV, o a MAS (en premsa b), sobre l'ocupació de l'espai agrari a Santa Margalida.

${ }^{39}$ Particulament Soto (1985-86) sobre el paper del grup familiar dintre del procés de colonització, i SoTo (1990 i 1991) sobre la forma en que es produeix l'ocupació de l'espai agrari als antics districtes d'Inca i Bunyola-Valldemossa.

${ }^{40}$ Miquel BARCELó (1988) ha posat de relleu les mancances dels estudis "documentalistes", fent una proposta de treball que partiria de la integració de la documentació escrita amb l'estudi de l'espai

${ }^{41}$ Efectivament, aquestes són les conclusions a les quals hom pot arribar mitjançant l'estudi documental de determinats sectors de l'illa, com ara e migjorn (districte de Manacor) (vegeu particularment SOTO, 1994a).

${ }^{42}$ Sobretot SOTO (1992) i JOVER (1992). El desenvolupament d'una ramaderia extensiva evidencia, un cop més, el "fracàs" de la colonització agrària.
} 
la serra de Tramuntana. Però també hi ha un segon tipus de poblament a zones diferents. Concretament, els citats treballs de Soto (1994), Barceló i Kirchner (1995) i Mas (en premsa b), sobre districtes del Migjorn i llevant de l'illa palesen unes formes de poblament diferents. Aquestes contrades es caracteritzen geogràficament per una menor disponibilitat d'aigua, unes terres més planes (menys tancades i determinades que les de muntanya, llavors) i una major distància de Ciutat. Les especials condicions geogràfiques no "determinen" les formes de poblament, que és sempre un factor humà (de fet, Pollença és més lluny de Palma que Sta. Margalida), però ajuden a comprendre'l. Ara bé, en definitiva, s'ha de tenir en compte que la "repoblació" de Mallorca no és un fenòmen deixat a la iniciativa lliure d'uns pagesos que, motu proprio, tendeixen a ocupar els llocs més favorables per al conreu i l'establiment humà, sinó que prèviament hi ha hagut un repartiment, i les terres han romàs (legalment almenys) en mans d'uns determinats senyors. Això, que suposaria donar tota la preeminència a la iniciativa senyorial, que així tendiria a dirigir tot el repoblament, no explicaria, tanmateix, que per exemple a les terres de Nunó Sanç apareguin dos tipus de repoblament tan diferents com els de l'antic districte de MûsûBunyûla i el de Manaqûr i Falanis, tot i que fora fàcil dir que, de fet, mort en 1241 el comte del Rosselló, es tracta més aviat d'un conjunt d'iniciatives combinades: reials en primer $\operatorname{lloc}^{43}$, de petits senyors, $\mathrm{i}$ individuals, de pagesos $^{44}$. Quina lògica determina l'ocupació de l'espai després de la conquesta, i al llarg del segle XIII?

Podem dir que a finals de segle la repoblació ha estat alhora un èxit i un fracàs. Tenim arguments en favor dels dos criteris: ha estat un èxit perque tota la illa està ocupada (la densitat és una altra qüestió) ${ }^{45}$; els drets

\footnotetext{
${ }^{43} \mathrm{O}$ més exactament dirigides pels administradors reials, ja que les terres de Nuno Sanç passaren a patrimoni reial.

${ }^{44}$ CATEURA (1988) va començar l'estudi de la repoblació noliliària de Mallorca per Nunó Sanç, però les pautes originàires (mòduls de 20 jovades, etc.) només són aplicables al període 1232-1241, i als nobles que l'acompanyaven.

${ }^{45}$ Santamaría (1990) parla de "apogeo demográfico" (pp. 371 i ss.) a partir de les dades del morabatí de 1329 , calculant la població entorn a uns 60.0000 habitants. Aquest "apogeo" seria indicatiu "de la adecuada política de desarrollo económico aplicada". El que resulta més important encara, aquest autor assenyala ( $p$. 376) que aquest marc polític $\mathrm{i}$ econòmic canalitzà l'emigració cap a Mallorca en triomfant competició amb el sud de Catalunya i el regne de València.
} 
reials pugen (senyal d'un augment demogràfic i d'una expansió agrària) ${ }^{46}$; creixen les viles; almenys en un nombre notable d'alqueries de l'època musulmana ha prosperat l'establiment de repobladors... Ha estat un fracàs perquè el procés d'immigració sembla lluny d'haver-se tancat (Mas, 1996); perque un bon nombre de les antigues explotacions apareixen abandonades; la ramaderia extensiva s'expandeix per districtes sencers de l'illa; perque a principis del XIV cal un procés de reassentament com el que suposen les Ordinacions de Jaume II.

Però crec que no té sentit plantejar-ho en aquests termes, d'èxit i/o fracàs, sinó més aviat en termes de canvi en la forma profunda d'ocupació del camp. Si hi ha quelcom en comú entre els "models" de muntanya/raïguer i els de llevant/migjorn és que en tots dos casos apareix una tendència a la concentració de la població en centres grans (viles i alqueries grans) i alhora a l'abandonament de determinades explotacions antigues, que, de fet, no s'arriben a repoblar mai (i en alguns casos el repoblament no té coninuitat). Aquest fenòmen, crec, constitueix la mateixa essència del canvi de Mayûrqa a Mallorca, i cal entendre'll bé. En definitiva, l'ocupació es faria seguint unes pautes molt concretes. En primer lloc, la feblesa i desarticulació de la població musulmana permet que a Mallorca "vigilar" els nadius no constitueixi una prioritat de l'ocupación ${ }^{47}$. En segon lloc, el fet de trobar un espai urbà i rural construït prèviament determinaria la selecció de les àrees de residència i de les zones d'explotació agrària; així, l'ocupació es dirigiria des de la perifèria de l'illa cap a l'interior i des dels centres més grans i poblats (consolidats) a centres més petits, molts dels quals ni tan sols s'arribarien a poblar. Per últim, el repartiment feudal deixaria en mans dels senyors la lògica de l'ocupació, que seria la de la producció de renda feudal, i no la de l'explotació directa de la terra. Això, que sembla contradictori amb la inexistència de reserva senyorial i l'aparent iniciativa camperola en l'ocupació i explotació de terres és l'únic que pot explicar, per exemple, el gran grau de sotsestabliments (malgrat la parcel-lació, de la que poden ser complementaris) produït en poc temps en un terreny que sembla lluny d'estar plenament ocupat.

\footnotetext{
${ }^{46}$ Els drets reials, evidentment, pugen (SOTO, 1997), però auesta font es troba molt mediatitzada pels problemes financers de Jaume II. Veure, per a això, CATEURA, 1986.

${ }^{47}$ Contràriament al cas de València, on la finalitat de les comunitats de colonitzadors sembla més aviat la de "controlar" la producció de renda dels nadius que no pas la de produir renda directament (TORRÓ, 1996).
} 


\section{Cloenda: DE NOU QuADRADO}

La visió quadradiana de la Història de Mallorca està molt lluny de ser superada, i no solament per inèrcia, encara que aquest sí pot constituir-ne un bon motiu en alguns $\operatorname{casos}^{48}$, sinó per funcionalitat. Per una banda, Quadrado va formular una sèrie d'afirmacions poc fonamentades documentalment, però que segurament es basaven en la visió quotidiana de molta documentació. Entre aquestes afirmacions es troben les referents al desenvolupament de la manufactura tèxtil al regne de Mallorca, i l'exportació de llana. En aquest sentit, els "antiquadradrians" militants hem de fer una autocrítica: dels molts treballs que hem produit, cap s'ha preocupat ni per la ciutat de Mallorca, ni per la manufactura ${ }^{49}$. També, per altra banda, Quadrado va ser el primer en relacionar el sector comercial i manufacturer amb els problemes polítics i socials de la monarquia mallorquina, encara que en un context cronològic posterior al segle XIII, naturalment. Per últim, la tendència historiogràfica recent (lligada a l'evolució ideològica motivada pels canvis econòmics i polítics dels 90 , que suposen bàsicament el desprestigi indicriminat del marxisme i la revaloració de les interpretacions neoclàssiques dintre del món acadèmic) tendeix a valorar sobretot els problemes referents al desenvolupament històric del mercat. Penso que aquests motius expliquen que l'historiador menorquí, més que "ser encara", "torni ser" un referent insustituible a l'hora d'interpretar globalment la història mallorquina.

Un bon exemple d'això és la recent obra d'Abulafia (1996) que s'esmentava a l'inici d'aquest treball, una síntesi d'història del regne de Mallorca des d'una òptica comercial i política exclussivament, partint del supòsit (quadradià) del caràcter "mercantil" i "lliure" de la societat mallorquina.

Ara bé, el capgirament que es va començar a produir a finals dels setantes amb l'obra d'en Miquel Barceló i el seu influxe no solament va servir per a revisar totalment la història de Mallorca, per a obrir noves

\footnotetext{
${ }^{48}$ En aquest sentit, comparteixo l'opinió d'ENSENYAT (1996) de que el "mestre" va ésser molt millor que els "deixebles". Com diu aquest autor, "Quadrado en posà els fonaments en la mesura que la historiografia posterior no només assumeix el plantejament sinó que l'assimila de manera crítica i, sobretot, amb escreix".

${ }^{49} \mathrm{Amb}$ la única excepció del treball de M. BERNAT (1995)
} 
perspectives i per a introduir metodologies innovadores, com ara l'arqueologia hidràulica, sinó que va produir una situació irreversible. Si, a partir d'ara, resulta ja impossible estudiar Mallorca sense tenir molt present l'estructuració de l'espai agrari dissenyat pels agricultors andalusins, també resulta impossible saber per què finalment van triomfar els feudals contra la revolta forana sense conéixer la forma en que el feudalisme establert a Mallorca va determinar l'ocupació real de l'illa (el procés de colonització), utilitzant els contractes d'establiment per a determinar on ocupar la terra, què produir, i deixant les mans lliures, en definitiva, als senyors, des del punt de vista jurídic, per tal de reconstituir els seus dominis territorials. Queda molta feina per fer, obviament, i entre aquesta la més perentòria consisteix en saber per què els senyors mallorquins van poder extendre un model basat en l'explotació directa i a Catalunya i país valencià això no va $\operatorname{passar}^{50}$.

\section{REFERÈNCIES BIBLIOGRÀFIQUES}

ABUlafiA, D. (1996) Un emporio mediterráneo. El reino catalán de Mallorca, Barcelona.

AGUILÓ, Capbreu ordenat l'any 1304 dels establiments y donacions fets per Don Nunó Sanç de la seua porció, "BSAL".

AlOMAR, G. (1976) Urbanismo regional en la Edad Media: las "Ordinacions"de Jaime II (1300) en el reino de Mallorca, Barcelona.

BARCEló, M. (1984) Sobre Mayûrqa, Palma.

\footnotetext{
${ }^{50}$ Això, precisament, és el que plantja G. JOVER (1992 i 1997)a la seva síntesi interpretativa sobre l'evolució de la societat mallorquina des de la conquesta fins al segle XIX. Per a aquest autor, més important que els repartiments i la repoblació feudals (1997 p. 257-263) és el fet de la desaparició, o inexistència, de reserva senyorial, mitjançant l'establiment de la terra als pagesos. La tendència d'aquests, al llarg del segle XIII i primera mietat del XIV, seria a escapolir-se del control feudal, mitjançant l'increment i millora de l'espai conreat. Però aquesta tendència xocaria frontalment amb el desenvolupament

d'una senyoria que tendeix a incrementar el seu control directe de la terra, el domini útil, per tal de desenvolupar la ramaderia llanar d'exportació. Encara que això ja es manifesta al XIV i principis del $\mathrm{XV}$, és òbviament la desfeta forana i la repressió subsegüent el que permet el definitu triomf senyorial, i Mallorca asisteix, simultàniament, a l'avortament d'un desenvolupament pagès "a la catalana" (àdhuc a la holandesa!) i d'un desenvolupament urbà manufacturer. La reacció senyorial crearà un model de latifundi exportador de llana amb creixent empobriment pagès, a l'anglesa, però (és clar) sense revolució industrial. Aquesta argumentació, brillant, creible, coherent i actual es pot trobar ja, implícitament, a Quadrado.
} 
Barceló, M., G. Rosselló Bordoy, M.A. Carbonero i R. Martí (1986. Les aigües cercades. Els qanât(s) de l'illa de Mallorca, Institut d'Estudis Baleàrics, Palma.

BARCELó, M. et alii (1988), Arqueología medieval. En las afueras del medievalismo, Barcelona.

BARCELÓ, M. (1995), Crear, disciplinar y dirigir el desorden. La renta feudal y el control del proceso de trabajo campesino: una propuesta sobre su articulación, "Taller d'Història", 6, 2n. semestre, pp. 61-72.

BARCELÓ, M. i KIRCHNER, H. (1995), Terra de Falanis. Felanitx quan no ho era. Assentaments andalusins al territori de Felanitx, Palma.

BARRIOS, A. (1985), Repoblación de la zona meridional del Duero. Fases de ocupación, procedencias y distribución espacial de los grupos repobladores", "Studia Storica", III/2, pp. 34-82.

BATET, C. i SoTO, R. (1997), Las donaciones a censo y los establecimientos como estrategia señorial (patrimonio Sentmenat, siglos X-XV), "VII Congreso de Historia Agraria", Salamanca, pp. 227-243.

BERNAT, M. (1995), Els "III Mesters de la Llana" a Ciutat de Mallorca (ss. XIV-XVII), Palma.

BISSON, J. (1968-72), Note statistique sur le Repartiment de Majorque, "BSAL", pp. 51-58.

BoIs, G. (1976), Crise du féodalisme, Paris.

BONNASSIE, P. (1980), Du Rhône à la Galice: genèse et modalités du régime féodal, Structures féodales et féodalisme dans l'Occident Méditerranéen, Colloque de l'École Française de Rome", pp. 17-56.

BSAL (Bulletí de la Societat Arqueològica Luliana), Palma.

BUSQUETS, J. (1947-52), El códice latinoarábigo del Repartimiento de Mallorca (parte latina), "BSAL", XXX, pp. 6-55.

BUSQUETS, J. (1954), El códice latinoarábigo del Repartimiento de Mallorca (texto árabe), "Homenaje a Millás Vallicrosa", vol. I, Barcelona, pp. 243-295.

CAMPANer, A. (1879), Numismática balear, Palma.

CAMPANER, A. (1881), Cronicón mayoricense. Noticias y relaciones históricas de Mallorca desde 1229 a 1800, Palma.

CARBONERO, M.A. (1982), El ma'jil de Banyalbufar (Mallorca). Memòria de llicenciatura, Universitat Autònoma de Barcelona. 
CARBONERO, M.A. (1988), Sistemes hidràulics i repartició col-lectiva de l'aigua a Mallorca: un model d'adaptació ecològica. Tesi de doctorat inèdita, Universitat Autònoma de Barcelona.

CATEURA, P. (1986), Mallorca a la segona meitat del segle XIII (Aspectes polítics i financers fins a 1276), "Estudis Baleàrics", 17, pp. 5786.

CATEuRa, P. (1988), La repoblació nobliària de Mallorca per Nunó Sanç, "Actes du XIIe Congrès d'Histoire de la Couronne d'Aragon", pp. 99-114.

Company Pons, J. (1975), Conquista cristiana, antecedentes, a Conquista de Mallorca. Reino de Mallorca (1229-1349) (tirada apart de la Historia de Mallorca dirigida per J. Mascaró Pasarius, pp. 1-89.

Cròniques: Les quatre grans cròniques: Jaume I, Bernat Desclot, Ramon Muntaner, Pere III, amb pròlegs i notes de Ferran Soldevila, Barcelona, 1971.

ENSENYAT, G. (1996), Josep Maria Quadrado, medievalista, i la historiografia actual, "Estudis Baleàrics", 55-56.

FontanA, J. (1982), Historia. Análisis del pasado y proyecto social, Barcelona.

FRB (Fontes Rerum Balearium), Palma.

Furió, A. \& GARCíA, F. (1983), El feudalisme medieval valencià: un assaig d'interpretació", "Debats", 5, pp. 33-42.

GoNZÁlEZ, J. (1990), Repartimientos andaluces del siglo XIII. Perspectiva de conjunto y problemas, De al Andalus a la sociedad feudal, CSIC, Institució Milà i Fontanals, Barcelona, pp. 94-118.

Guichard, P. (1976), Al Andalus. Estructura antropológica de una sociedad islámica en occidente, Barcelona.

GuICHARD, P. (1977), Estructures sociales "orientales" et "occidentales" dans l'Espagne musulmane, Paris.

GuichaRd, P. (1980), Le problème de l'existence des structures féodales dans la societé d'al Andalus (l'exemple de la région valencienne), Structures féodales et féodalisme dans l'Occident Méditerranéen, pp. 699725.

JENÉ, A. (1985-86), La conquesta de Manûrqa al febrer de 1287, La formació $i$ expansió del feudalisme català. "Actes del col-loqui organitzat pel Col-legi Universitari de Girona (8-11 de gener de 1985)", ("Estudi General", 5-6), pp. 389-401. 
JOVER, G. (1992), Una crisi de la renda feudal? Mallorca, 1330-1500, "Estudis d'Història Econòmica", 1992/1, pp. 31-55.

JOVER, G (1997), Societat rural $i$ desenvolupament econòmic a Mallorca. Feudalisme, latifundisme i pagesia, 1500-1800. Tesi de doctorat inèdita, Universitat de Barcelona.

KIRCHNER, H. (1993), La construcció de l'espai pagès: les valls de Bunyola, Orient, Coanegra $i$ Alaró a Mayûrqa. Tesi doctoral inèdita, Universitat Autònoma de Barcelona.

LliTERAS, L. (1967), Artá en el siglo XIII, Palma.

LOURIE, E. (1970), Free moslems in the Balearics under Christian rule in the Thirteenth century, "Speculum", XIV/4, pp. 624-649.

MARTí, R. (1988) V. BARCELÓ, M. et alii, Les aigües cercades.

MAS (1994), El procés repoblador a Mallorca durant la primera meitat del segle XIV. Una aportació al seu estudi, "BSAL", 50, pp. 167-198.

MAS, A. (en premsa a), La polèmica sobre la supressió del règim senyorial a Mallorca.

MAS, A. (en premsa b), La parròquia de Santa Margalida, 1229-1450. Petits senyors $i$ grans pagesos?

MoRA, P. \& ANDRINAL, L. (1982), Diplomatari del monestir de Santa Maria la Real de Mallorca (1232-1360), Palma.

Mut, A. \& Rosselló, G. (1993), La remembrança de Nunyo Sanç. Una relació de les seves propietats a la ruralia de Mallorca, Palma.

OLEZA, J. (1928-29, 1930-31, 1944-46, 1947-52 I 1953-60) Caballerias de Mallorca, "BSAL".

PASTOR, R. (1980), Sur l'articulation des formations économicosociales: communautés villagoeises et seigneuries au nord de la peninsule ibèrique (X-XIII siècles), Structures féodales et féodalisme dans l'Occident Méditerranéen, pp. 193-216.

PASTOR, R. (1986), Estructuras feudales y feudalismo en el mundo mediterráneo, Barcelona.

PÉREZ, L. (1977 i 1978), Corpus documental balear. Epoca de Jaime $I$, "FRB".

PIÑA Homs, R. (1977), El Gran e General Consell, asamblea del reino de Mallorca, Palma.

PORTElla, J. (1983), La conquesta catalana i l'estructuració d'una nova formaciós social a Mallorca. Un estat de la qüestió, "I Col·loqui 
d'Història Agrària" (Barcelona, 13-15 octubre de 1978), València, Institució Alfons el Magnànim, pp. 119-131.

PORTElla, J. (1984), Mallorca: la consolidación del feudalismo, a Historia de los pueblos de España. Los antiguos territorios de la Cortona de Aragón, dirigit per M. Barceló, Barcelona, pp. 131-146.

PORTElla, J. (1985-86), La colonització feudal de Mallorca: els primers establiments de l'alqueria Deià (1232-1285), La formació $i$ expansió del feudalisme català, "Actes del Col-loqui organitzat pel Col-legi Universitari de Girona (8-11 de gener de 1985)", ("Estudi General", 5-6), pp. 331343.

PORTELla, J. (1994), Les baronies i cavalleries de Mallorca dels segles XIII $i$ XIV. In feudum ad consuetudinem Barchinone, "Afers", 18, pp. 427441.

Poveda (1978), La toponímia àrabo-musulmana de Mayûrqa según la documentación catalana del siglo XIII. Memòria de llicenciatura, Universitat Autònoma de Barcelona.

PovedA, A. (1987), Toponímia àrabo-berber i espai social a les Illes Orientals d'al Andalus. Tesi de doctorat inèdita, Universitat Autònoma de Barcelona.

QUADRADO, J.M. (1847), Forenses y ciudadanos, Palma.

QUADRADO, J.M. (1850), La conquista de Mallorca, Palma.

RIBAS DE PINA, M. (1934), La conquista de Mallorca pel rei en Jaume I. Estudi tècnic militar, Mallorca.

RIERA, A. (1980), La llicència per a barques de 1284, "FRB", III, pp. 121-140.

RIERA, A. (1986), La Corona de Aragón y el reino de Mallorca en el primer cuarto del siglo XIV, Madrid-Barcelona.

RIU, M. (1990), Algunes fonts $i$ la bibliografia dels deu darrers anys sobre el regne privatiu de Mallorca, "XIII Congrés d'Història de la Cororona d'Aragó (Palma 27 setembre-1 octubre 1987)", Institut d'Estudis Baleàrics, Palma, pp. 119-138.

RodrígueZ, A. (1982), El territori de Pollença sota el Temple, 12981304. Memòria de llicenciatura, Universitat Autònoma de Barcelona.

RodrígueZ, A. (1985-86), Conquesta $i$ feudalització: el cas de Pollença, Mallorca (1298-1304), La formació $i$ expansió del feudalisme català, "Actes del Col-loqui organitzat pel Col-legi Universitari de Girona (8-11 de gener de 1985) ("Estudi General", 5-6), pp. 371-387. 
RODRÍGUEZ, A. (1994), Dos moments en la colonització feudal del norest de Mallorca:1298/1304-1319/1325), "Afers", 18, pp. 367-403.

ROSSELlÓ VAQUER, R. (1972), Felanitx a mitjan segle XIII, Felanitx.

RosSElló VAQUer, R. (1973), Felanitx a la segona meitat del segle XIII, Felanitx.

Rosselló Vaquer, R. (1978), Inca i Selva en el segle XIII, Palma.

ROSSElló VAQUeR, R. \& FERRER, R. (1978), Història de Manacor en el segle XIII, Palma.

SALVÁ, J. (1975), Instituciones Políticas y Sociales otorgadas por Jaime I a los pobladores de Mallorca (tirada apart de Historia de Mallorca, dirigida per J. Mascaró Pasarius, III, p. 361 ss., Palma.

SANTAMARÍA, A. (1981), En torno a la evolución del modelo de sociedad en el Reino de Mallorca (siglos XIII-XVIII), "Estudis Baleàrics", I/3, pp. 1-195.

SANTAMARÍA, A. (1987), La carta de franquesa de Mallorca, estatuto constituyente del reino, "Estudios dedicados a la memoria del profesor Emilio Sáez", CSIC, Institució Milà i Fontanals, Barcelona, pp. 208-228.

SANTAMARÍA, A. (1989), Repoblación y sociedad en el reino de Mallorca (1230-1343), "Revista de la Facultad de Geografía e Historia", 4, pp. 525-540.

Santamaría, A. (1990), Ejecutoria del reino de Mallorca, Palma.

SoldeVILA, F. (Vegeu Cròniques).

Sото, R. (1978), Assaig de reconstrucció d'alguns ayza', alqueries $i$ rahals segons els protocols catalans de l'Escrivania de Cartes Reials de Ciutat (1232-1276) $i$ els Llibres del Repartiment. Memòria de llicenciatura, Universitat Autònoma de Barcelona.

SoTO, R. (1984), Introducció, notes i transcripció del Còdex Català del Repartiment de Mallorca, Palma.

Soto, R. (1985-56), Alguns casos de gestió colonial' feudal a la Mallorca del segle XIII, La formació i expansió del feudalisme català. "Actes del Col-loqui organitzat pel Col-legi Universitari de Girona (8-11 de gener de 1985) ("Estudi General" 5-6), pp. 345-369.

Sото, R. (1990) "Repartiment" $i$ "repartiments": l'ordenació d'un espai de colonització feudal a la Mallorca del segle XIII, "De al Andalus a la sociedad feudal", CSIC, Institució Milà i Fontanals, Barcelona, pp. 1-51. 
Soto, R. (1991), L'ordenació de l'espai $i$ les relacions socials a Mallorca en el segle XIII (1229-1301). Tesi de doctorat inèdita, Universitat Autònoma de Barcelona.

Sото, R. (1992), Ovelles, vaques, porcs $i$ eclesiàstics (Algunes consideracions sobre la ramaderia balear a l'Edat Mitjana, segles XI-XIV), "Estudis d'Història Econòmica", 1992/1, pp. 13-29.

Soto, R. (1994a), La porció de Nuno Sanç. Repartiment i repoblació de les terres del Sud-est de Mallorca, "Afers", 18, pp. 347-365.

Soto, R. (1994b), La situació dels andalusins (musulmans $i$ batejats) a Mallorca després de la conquesta catalana de 1230, "Mélanges de la Casa de Velázquez", XXX/1, pp. 167-206.

SoTo, R. (1996), Alguns homes rics (el paper dels jueus de Mallorca durant el segle XIII), "Butlletí de la Societat Catalana d'Estudis Històrics" (BSCEH, VII, pp. 27-40).

SoTо, R. (1997), Patrimoni reial i transformacions agràries a Mallorca en el segle XIII, "Col-loqui Corona, municipis i fiscalitat a la Baixa Edat Mitjana", Lleida, novembre de 1995, pp. 555-573

TORRó, J. (1996), Colonització feudal i resistència andalusina al regne de València. La frontera meridional. Tesi doctoral inèdita, Universitat de València.

TOUBERT, P. (1973), Les structures du "Latium" médiéval. Le "Latium" méridional et la Sabine du IX siècle au XII siècle, Roma.

TOUBERT, P. (1990), Castillos, señores y campesinos en la Italia medieval, Barcelona.

TREPPO, M. del (1976), Els mercaders catalans $i$ l'expansió de la corona catalano-aragonesa, Barcelona. Palma.

VIC, J. \& MUNTANER, J. (1945), Documenta Regni Majoricarum,

\section{RÉSUMÉ}

Il ne s'agit pas de faire un simple inventaire bibliographique des nouveautés sur le XIII siècle majorquin (auparavant rares, bien que quelquefois très importants) mais plutôt une mise en valeur de celles-là. À mon avis, l'historiographie sur le royaume de Majorque se trouve, encore, lourdement influencée par l'historien du XIX ${ }^{\mathrm{e}}$ siècle J.M. Quadrado, brillant défenseur du conservatisme sous un vernis liberal. Ça veut dire, d'abord, qu'on nie l'existence de relations féodales à Majorque, et l'on y affirme une identité marchande presque 
"bourgeoise". Il n’y a qu'à lire les plus récents apports internationaux (par exemple de David Abulafia) pour trouver ce point de vue absolument débassé. Le but de ce travail est ce de rappeler qu'il y a "une autre" histoire médiévale de Majorque (inspirée, inicialement par Miquel Barceló), qui, en partant de l'étude de la societé andalousi précedente, met en évidence que la conquête et la colonisation du nouveau royaume résultent d'un processus dominé par la rente féodale, bien qu'influencé par les pouvoirs royaux et marchands.

\section{SUMMARY}

Although there is some new (and at times interesting) literature on Majorca in the 13th. century, I do not intend to make a list but an evaluation of it. It is my view that the literature on the kingdom of Majorca is still heavily influenced by the 19th. historian J.M. Quadrado, a brilliant representative of conservatism behind a liberal mask. He denies the existence of feudal relationships in Majorca, postulating a commercial identity almost "bourgeois". The mere reading of the latest international contributions (by David Abulafia, for instance) is enough to corroborate the prominence of this view. The aim of this paper is to bring to mind the existence of "another" Medieval History of Majorca (especialy under the aegis of Miquel Barceló), which, starting from the previous Andalusi society, conceptualizes the conquest and colonisation of the new Kingdom as a process led by the feudal tax, although in combination with the royal and mercantile powers. 